\title{
Global retrieval of marine and terrestrial chlorophyll fluorescence at its red peak using hyperspectral top of atmosphere radiance measurements: Feasibility study and first results
}

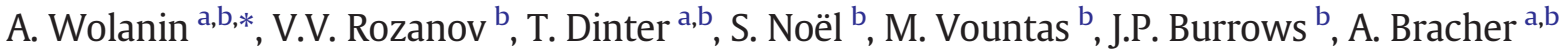 \\ a Alfred-Wegener-Institute Helmholtz-Centre for Polar and Marine Research, Bussestr. 24, 27570 Bremerhaven, Germany \\ b Institute of Environmental Physics, University of Bremen, Otto-Hahn-Allee 1, 28359 Bremen, Germany
}

\section{A R T I C L E I N F O}

\section{Article history:}

Received 21 March 2014

Received in revised form 31 March 2015

Accepted 20 May 2015

Available online 2 July 2015

\section{Keywords:}

Sun-induced fluorescence

Retrieval

SCIAMACHY

GOME-2

Fraunhofer-line approach

Hyperspectral remote sensing

Ocean-atmosphere coupled radiative transfer

\begin{abstract}
A B S T R A C T
Chlorophyll fluorescence is directly linked to the physiology of phytoplankton or plants. Here, we present a new satellite remote sensing approach to retrieve chlorophyll fluorescence at its red peak ( $685 \mathrm{~nm})$ by using measurements from the hyperspectral instruments SCanning Imaging Absorption SpectroMeter for Atmospheric CHartographY (SCIAMACHY) and Global Ozone Monitoring Experiment-2 (GOME-2). This method, which is based on the Differential Optical Absorption Spectroscopy (DOAS) technique, was used to exploit narrow spectral structures resulting from the filling-in of the Fraunhofer Fe I line, which originates from fluorescence. The reference spectra for chlorophyll fluorescence were calculated by the coupled ocean-atmosphere radiative transfer model SCIATRAN. We compared our results on marine chlorophyll fluorescence observations with the MODIS Terra normalized Fluorescence Line Height ( $\mathrm{nFLH}$ ) product for the average of years 2003-2011 and year 2009. Our method also enables the retrieval of chlorophyll fluorescence above land vegetation scenes. The results for the fluorescence observed above terrestrial vegetation for July and December 2009 were compared to MODIS Enhanced Vegetation Index (EVI). The comparisons show good spatial agreement between different retrievals providing evidence for the good performance of our algorithm. The method presented is generic and can be applied to other hyperspectral instruments in the future. Having established the retrieval technique, extensive studies of chlorophyll fluorescence will improve global knowledge on physiology and photosynthetic efficiency, in both the marine and terrestrial realms, and its dependence on environmental factors.
\end{abstract}

(c) 2015 Elsevier Inc. All rights reserved.

\section{Introduction}

Marine and terrestrial carbon pools are important reservoirs in the carbon cycle, and they absorb a significant part of the emitted carbon dioxide from fossil fuel combustion (IPCC, 2013). It is clear that due to land-use changes worldwide, areas of pristine vegetation have been decreasing, e.g., the deforestation of the rainforest. With respect to the oceanic biosphere, there is an ongoing discussion about the changes in health, composition and abundance of phytoplankton (Doney et al., 2012). It has been reported that the biomass of phytoplankton has declined significantly in the last decades at all scales (Boyce, Lewis, \& Worm, 2010; Gregg, 2003) and this decline is expected to continue (Hofmann, Worm, Rahmstorf, \& Schellnhuber, 2011; Olonscheck, Hofmann, Worm, \& Schellnhuber, 2013). However, the results of Boyce et al. (2010) have been questioned (Mackas, 2011; McQuatters-Gollop et al., 2011; Rykaczewski \& Dunne, 2011), and studies showing the opposite sign have been published claiming that phytoplankton has been

\footnotetext{
* Corresponding author at: Alfred-Wegener-Institute Helmholtz-Centre for Polar and Marine Research, Bussestr. 24, 27570 Bremerhaven, Germany.

E-mail address: Aleksandra.Wolanin@awi.de (A. Wolanin).
}

increasing within the last years on both regional (e.g., McQuattersGollop et al., 2007) and global scales (Gregg, Casey, \& McClain, 2005). Other studies have also shown that the ocean regions should be studied separately, as there are opposite trends for different regions worldwide (Siegel, 2010; Wernand, van der Woerd, \& Gieskes, 2013).

Phytoplankton is responsible for about half of the estimated global net primary production of carbon (Field, 1998). Moreover, because of a rather short turnover rate of phytoplankton organic matter, in the order of a week (Falkowski, 1998), and changing phytoplankton growth conditions in response to changing physical and chemical parameters of the ocean, phytoplankton abundance and community structure constantly change in time and space. Consequently, in order to assess accurately the amount of phytoplankton and to identify its change, global observations require a reasonable temporal and spatial resolution in order to resolve their intrinsic natural variability. Observations from instrumentation on polar orbiting sun synchronous satellites have facilitated the study of changes in the phytoplankton biomass having a temporal sampling of a day and a spatial resolution on the order of a km. Recently, in addition to chlorophyll concentration products, ocean color products of other oceanic parameters have also been retrieved from measurements made by satellite-based instrumentation, e.g., particulate organic 
carbon, particulate inorganic carbon, euphotic depth, and fluorescence line height (e.g., see http://oceancolor.gsfc.nasa.gov).

Information about chlorophyll fluorescence has been used to assess the physiological state of phytoplankton, as a result of its relationship to photosynthetic efficiency (Falkowski \& Kolber, 1995). Photosynthesis is the process by which light energy is transformed into chemical energy and fixes atmospheric carbon dioxide into sugars. Oxygenic photosynthesis is responsible for virtually all of the biochemical production of organic matter (Field, 1998). The first elementary step in photosynthesis, the absorption of solar radiation in the visible part of the spectrum, takes place in the thylakoid membrane, where two pigmented functional units, photosystem II (PS II) and photosystem I (PS I), are located. Photosystems carry out the primary photochemistry of photosynthesis: the absorption of light and the transfer of energy and electrons. When chlorophyll-a (chl-a) molecules absorb light, a fraction of the energy absorbed is re-emitted as fluorescence. Although both photosystems contain chl-a pigments that contribute among other pigments to light absorption, the majority (95\%) of fluorescence originates from chl-a of PS II and only a small contribution is emitted from PS I (Krause \& Weis, 1991). However, for the second peak of fluorescence at longerwavelengths ( $735 \mathrm{~nm})$, PS I can contribute up to $40 \%$ to the fluorescence signal (Agati, Cerovic, \& Moya, 2000).

In vivo, the efficiency of fluorescence is around $1 \%$ (Behrenfeld et al., 2009; Maxwell, 2000 and references therein). The fluorescence signal is clearly stronger in regions with high phytoplankton biomass and low in depleted areas, as the fluorescence of chl-a occurs only when the molecule is present in the water column. The relationship between fluorescence and chl-a is curvilinear as a result of pigment packaging. This is because fluorescence is proportional to the concentration of the excited electronic state of chl-a, which depends on the number of photons absorbed by chl-a and the quenching and other reactions of this excited state. As incident irradiance is highly variable (due to clouds, surface wave focusing, etc.), phytoplankton use three processes to protect themselves from excessive solar electromagnetic radiation: photoadaptation, photoacclimation and photoregulation (Huot \& Babin, 2010). When incident photosynthetically active radiation (iPAR) increases, the absorbed light energy proportionally increases, but the absorbed energy for charge separation and photochemistry is limited. As photochemistry saturates, the fluorescence increases; however, additional processes are invoked to dissipate the excess energy in order to minimize photodamage. These processes are collectively termed nonphotochemical quenching (NPQ) and they dissipate excess absorbed energy as heat.

Chl-a fluorescence changes in response to phytoplankton physiology. Consequently, monitoring these changes could be helpful in the characterization of photosynthesis, health and the productivity of oceans at global scales (Babin, Morel, \& Gentili, 1996; Lichtenthaler \& Rinderle, 1988). For example, they reflect the effect of nutrient limitations, e.g., macro-nutrients (Abbott \& Letelier, 1999; Schallenberg, Lewis, Kelley, \& Cullen, 2008) or iron (Behrenfeld et al., 2009). Chl-a fluorescence also depends on species composition (MacIntyre, Lawrenz, \& Richardson, 2010) and growth irradiance, i.e., irradiance that phytoplankton has experienced during the growth phase of the cells and hence to which it is acclimated (e.g., Morrison \& Goodwin, 2010; O'Malley et al., 2014).

The marine chl-a fluorescence has been retrieved from space by the multispectral instruments MODIS and MERIS. The fluorescence line height algorithm (FLH) designed for MODIS (Abbott \& Letelier, 1999), later also applied to the MERIS instrument (Gower, Brown, \& Borstad, 2004), derives the strength of the fluorescence signal by comparing radiance in the fluorescence channel to background radiance. MODIS and MERIS are high spatial resolution low spectral resolution instruments, both having bands in the visible spectral region dedicated to fluorescence measurements. For MODIS, the radiances are measured in three channels in $10 \mathrm{~nm}$ windows, two of which are used to account for other effects (backscatter and Raman scattering) by calculating the 'baseline radiance' for fluorescence through interpolation of measurements at $667 \mathrm{~nm}$ (band 13) and $748 \mathrm{~nm}$ (band 15), the latter one being far from fluorescence emission due to water vapor absorption lines near $730 \mathrm{~nm}$. The third band, the fluorescence band, is centered at $678 \mathrm{~nm}$ (band 14). This band does not cover the maximum of the fluorescence signal at $685 \mathrm{~nm}$ in order to avoid oxygen absorption features (Abbott \& Letelier, 1999). Because of these limitations on band placement, the measured MODIS FLH will respond to only $57 \%$ of the actual fluorescence signal (Gower et al., 2004). In the case of the MERIS instrument, the FLH algorithm uses bands 7, 8 and 9, located at $665 \mathrm{~nm}$, $681 \mathrm{~nm}$ and $709 \mathrm{~nm}$, respectively, and hence measured MERIS FLH will respond to $78 \%$ of the actual fluorescence signal (Gower et al., 2004). FLH is calculated with water leaving radiances, while nFLH (normalized FLH) uses normalized water leaving radiances. The schematic of the algorithm and corresponding positions of relevant MODIS and MERIS bands are shown in Fig. 1. Using the following algorithm, nFLH for MODIS is calculated:

$\mathrm{nFLH}=L_{W N, 14}-L_{W N, 15}+\left(L_{W N, 13}-L_{W N, 15}\right) *\left[\left(\lambda_{15}-\lambda_{14}\right) /\left(\lambda_{15}-\lambda_{13}\right)\right]$,

where $L_{W N}$ are the normalized water leaving radiances of the MODIS band number given by the subscript; nFLH is currently a MODIS Level 3 standard product (available online at http://oceancolor.gsfc.nasa. gov/cgi/l3).

MODIS nFLH delivered the first global picture of marine fluorescence and initiated global studies of phytoplankton physiology and productivity (Behrenfeld et al., 2009; Huot, Franz, \& Fradette, 2013; McKibben, Strutton, Foley, Peterson, \& White, 2012; Morrison \& Goodwin, 2010; Westberry, Behrenfeld, Milligan, \& Doney, 2013). However, detecting a weak fluorescence signal accurately is challenging. Atmospheric correction applied to multispectral data makes several assumptions about atmospheric effects for different wavelength regions and the nFLH algorithm assumes the shape of the emission function. In case of the MODIS nFLH retrieval, further problems may arise from backscattered light by particulate matter that scatter light in the red wavelengths and from which some nFLH signals originate (Abbott \& Letelier, 1999). Negative values of nFLH were also observed during blooms of some cyanobacteria species (Wynne et al., 2008), which was later used for a cyanobacterial bloom forecast system in Lake Erie (Wynne, Stumpf, Tomlinson, et al., 2013).

We present in this manuscript a new method for the detection of phytoplankton fluorescence utilizing hyperspectral measurements. Hyperspectral satellite data are not traditionally used in optical remote sensing of the oceans, but have already proven to be an interesting and useful tool in studies of the photic zone by identifying vibrational Raman scattering and phytoplankton composition (Bracher et al., 2009; Sadeghi et al., 2012; Vountas, Dinter, Bracher, Burrows, \& Sierk, 2007). The hyperspectral instrument TANSO-FTS onboard the Japanese GOSAT satellite has been used to detect land fluorescence (Frankenberg et al., 2011; Guanter et al., 2012; Joiner et al., 2011) with promising results. Unfortunately, the method developed for fluorescence from terrestrial plants, cannot be used for marine chl-a fluorescence, because TANSOFTS does not observe wavelengths of visible phytoplankton fluorescence emission. More recently, the land fluorescence signal was also retrieved from the GOME-2 instrument (Joiner et al., 2013), which also covers the spectral range of marine fluorescence.

We present in this manuscript a new approach to retrieve the chl-a fluorescence signal, emanating from the marine and the terrestrial biosphere, from measurements of nadir sounding hyperspectral passive remote sensing spectrometers. The retrieval has been developed using the level 1 SCIAMACHY (SCanning Imaging Absorption SpectroMeter for Atmospheric $\mathrm{CHartographY}$ ) data, but has also been applied to data from GOME-2 (Global Ozone Monitoring Experiment-2). The method developed is generic and can also be applied to other hyperspectral instruments. In this feasibility study we demonstrate that the hyperspectral 


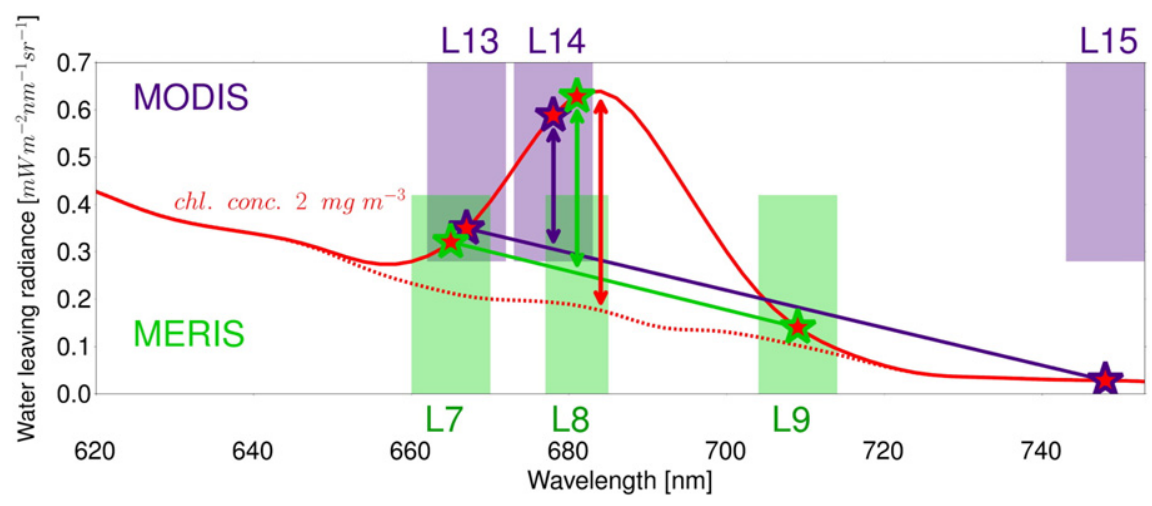

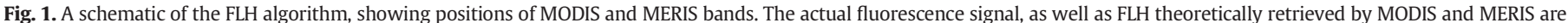

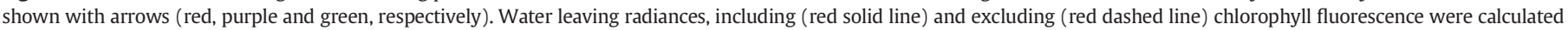
with the radiative transfer model SCIATRAN for a chl-a concentration of $2 \mathrm{mg} / \mathrm{m}^{3}$.

observations of the upwelling radiation at the top of the atmosphere have the potential to observe the chl-a fluorescence. The retrieval presented here will be beneficial for current and future studies on marine phytoplankton and terrestrial vegetation.

The manuscript is organized as follows: we describe briefly the DOAS method in Section 2.1. The reference spectra of chl-a fluorescence and other components needed for the DOAS retrieval are introduced in Section 2.2. The chl-a fluorescence retrieval technique is described in detail in Section 2.3. The SCIAMACHY and GOME-2 instruments, to which our retrieval was applied, are described in Section 2.4. SCIAMACHY and GOME-2 results along with their comparison to other retrievals are presented and discussed in Section 3. We summarize our study in Section 4

\section{Methods}

\subsection{Retrieval technique: DOAS}

In order to retrieve the fluorescence signal from high spectrally resolved satellite data, a modified approach, based on the Differential Optical Absorption Spectroscopy (DOAS) technique (Perner \& Platt, 1979) was used. DOAS was originally developed for active long path remote sensing (Perner \& Platt, 1979), but then was extended for passive remote sensing on-ground observations (e.g., Eisinger, Richter, LadstätterWeißnmayer, \& Burrows, 1997 and references therein). The DOAS retrieval approach utilizes the separation of high frequency from low frequency spectral features in wavelength space. Variants of this approach have been applied for several years for remote sensing of atmospheric trace gasses (e.g., Burrows et al., 1999; Richter, Burrows, Nüß, Granier, \& Niemeier, 2005), and has been lately extended to the aquatic domain as PhytoDOAS (Bracher et al., 2009; Sadeghi et al., 2012; Vountas et al., 2007). The theoretical consideration of the relationships between different DOAS algorithms is given by Rozanov and Rozanov (2010). The family of DOAS algorithms exploits the fingerprint spectral features in backscattered solar radiance spectra that are caused by i) molecular absorption by atmospheric constituents (e.g., Richter et al., 2005), ii) spectral re-distribution features that are induced by inelastic processes in the atmosphere and ocean and fill in the solar Fraunhofer lines (e.g., Vasilkov, 2002; Vountas, Rozanov, \& Burrows, 1998; Vountas et al., 2007), and iii) absorption features from terrestrial plants and marine phytoplankton (e.g., Bracher et al., 2009; Wagner, Beirle, Deutschmann, Grzegorski, \& Platt, 2007).

Inelastic processes (Raman scattering, Brillouin scattering and fluorescence) lead to a redistribution of solar backscattered electromagnetic radiation and a shift of the frequency toward higher or lower energy. Inelastic scattering by molecules in the air (mostly $\mathrm{N}_{2}$ and $\mathrm{O}_{2}$ ) is called the rotational Raman scattering (RRS). In lakes, rivers and oceans there are two dominant inelastic processes: vibrational Raman scattering by water molecules (VRS), and fluorescence of phytoplankton pigments, mainly chl-a, and colored dissolved organic matter (CDOM). The effect of those processes on the backscattered radiation at the top of atmosphere is possibly identified in the filling-in of Fraunhofer lines (spectrally narrow and often saturated absorption features in the solar spectrum), known as the Ring effect after its discoverer James Ring (Grainger \& Ring, 1962). The Brillouin scattering, which also may fill in Fraunhofer lines, is typically smaller than the spectral resolution of SCIAMACHY and GOME-2 and is not considered further here. The impact of the Brillouin scattering on the spectral structure of the radiation reflected from the ocean surface can be found in Peters et al. (2014).

The DOAS method determines the amount of molecular absorbers along the effective optical light path by fitting and scaling spectra within a given wavelength window. The broad-band effects (e.g., Rayleigh and Mie scattering) are removed by a low-degree polynomial that is also fitted. The fitting in the DOAS method is formalized as a least-squares minimization and is described by the following equation:

$\left\|\tau(\lambda)-\sum_{i=1}^{N} \sigma_{i}(\lambda) S_{i}-\sigma_{R}(\lambda) S_{R}-\sigma_{V}(\lambda) S_{V}-\sigma_{f}(\lambda) S_{f}-\sum_{k=0}^{K} a_{k} \lambda^{k}\right\|^{2} \rightarrow \min$.

Here, $\tau(\lambda)=-\ln \frac{I(\lambda)}{I_{0}(\lambda)}$ is the so-called slant optical density, $I(\lambda)$ and $I_{0}(\lambda)$ are the measured backscattered radiance and extraterrestrial irradiance, respectively, $\sigma_{i}(\lambda)$ is the absorption cross-section of the $i$ th atmospheric absorber, $N$ is the number of absorber, $\sigma_{R}(\lambda), \sigma_{V}(\lambda)$, and $\sigma_{f}(\lambda)$ are reference spectra of RRS, VRS and chl-a fluorescence, respectively, $\sum_{k=0}^{K} a_{k} \lambda^{k}$ is the low order polynomial, typically of the order $K \leq 4$. The ratio of $I(\lambda)$ and $I_{0}(\lambda)$ is taken in order to make it less sensitive to absolute radiometric calibration.

The minimization is carried out with $S_{i}, S_{R}, S_{V}, S_{f}$ and polynomial coefficients as the fitted parameters. The parameter $S_{i}$ is the integrated number density of the $i$ th atmospheric absorber along the slant optical path, which is generally related to the concentration of a given absorber, and $S_{R}, S_{V}$, and $S_{f}$ parameters are called scaling or fit factors and carry information about the strength of the corresponding inelastic process. The method can be applied to SCIAMACHY and GOME-2 data or similar data sets, which make measurements of both extraterrestrial radiation, $I_{0}(\lambda)$, as well as backscattered radiation, $I(\lambda)$, with sufficient spectral resolution.

\subsection{Reference spectra and spectral windows}

In order to perform the chl-a fluorescence retrieval with the DOAS method, an adequate reference spectrum has to be determined for use 
as a priori information. Because the effect of inelastic processes on the top of atmosphere radiation can be modeled, the reference spectra were calculated following Vountas, Richter, Wittrock, and Burrows (2003) as:

$\sigma_{j}(\lambda)=\ln \frac{I^{+}(\lambda)}{I^{-}(\lambda)}, \quad j=R, V, f$

where $I^{+}(\lambda)$ and $I^{-}(\lambda)$ are the modeled radiances at the top of atmosphere calculated accounting for the $j$ th inelastic process and neglecting all inelastic processes, respectively.

The radiances $I^{+}(\lambda)$ and $I^{-}(\lambda)$ have been calculated using the coupled ocean-atmosphere radiative transfer model SCIATRAN (Blum, Rozanov, Burrows, \& Bracher, 2012; Rozanov, Rozanov, Kokhanovsky, \& Burrows, 2014). The details of the solution and the verification of the radiative transfer equation including the rotation Raman scattering in the atmosphere can be found in Rozanov \& Vountas (2014) and Vountas et al. (1998). The implementation of inelastic processes (such as VRS and chl-a fluorescence) was performed in SCIATRAN following Haltrin and Kattawar (1993). The verification of VRS was achieved by comparing the VRS reference spectra with model data (Kattawar \& Xu, 1992), as well as with VRS spectra, obtained from hyperspectral shipborne measurements of the solar radiation reflected from the ocean surface (Peters et al., 2014). The accuracy of the implementation of chlorophyll fluorescence has not been verified by a dedicated study, but the method is similar to that used for VRS. The fluorescence emission function was modeled by a Gaussian:

$f^{e m}(\lambda)=\frac{1}{\sqrt{2 \pi} \sigma_{1}} \exp \left[-\frac{\left(\lambda-\lambda_{1}^{0}\right)^{2}}{2 \sigma_{1}^{2}}\right]$,

where $\lambda_{1}^{0}=685 \mathrm{~nm}$ is the wavelength of maximum emission and $\sigma_{1}=$ $10.6 \mathrm{~nm}$ is the standard deviation of the Gaussian, which corresponds to a value of $25 \mathrm{~nm}$ for the full width at half maximum of the emission band (Mobley, 1994). The chl-a concentration and quantum efficiency of fluorescence were set to $1 \mathrm{mg} / \mathrm{m}^{3}$ and to 0.02 , respectively, homogeneously in the $100 \mathrm{~m}$ deep water column. The radiative transfer calculations were performed in the spectral range of $370-720 \mathrm{~nm}$, where the chlorophyll-a fluorescence excitation wavelength range is 370$690 \mathrm{~nm}$ and emission wavelength range is $650-720 \mathrm{~nm}$. The absorption of chlorophyll was taken into account in the whole spectral range of 370-720 nm, including the red peak absorption.

The DOAS retrieval technique, generally and as implemented in this study, is sensitive to errors resulting from correlations between the reference spectra in the fit, i.e., the fit algorithm will not be able to distinguish between similar spectral features originating from different sources. Unfortunately, all inelastic processes have similar spectral behavior, as they all lead to the filling-in of Fraunhofer lines. Hence, some of the retrieved signal does not originate from fluorescence, but from Raman scattering. As in the wavelength region where chlorophyll fluoresces Raman scattering is not negligible, an optimal selection of the spectral region is essential. Ideally a window where fluorescence is at its strongest and Raman scattering is relatively weak, is required. The choice of the fitting wavelength region is also limited by strong atmospheric absorption features of $\mathrm{O}_{2}$ and water vapor. These regions are avoided because they attenuate the solar radiation and for that matter the fluorescence. The selection of an optimal spectral fitting window is critical for optimal retrieval because marine fluorescence itself is a very weak signal (Abbott \& Letelier, 1999; Neville \& Gower, 1977).

The deepest Fraunhofer lines in the chl-a fluorescence region, which lead to the strongest features of filling-in, are $\mathrm{H} \alpha$ and Fe I. Although the Fraunhofer $\mathrm{H} \alpha$ line at $656 \mathrm{~nm}$ is the strongest, it was not used in this work, because it is in a region of weak fluorescence and where rotational and vibrational Raman scattering is relatively strong. This wavelength region is also substantially affected by water vapor absorption. The second deepest Fraunhofer line is the Zeeman triplet line Fe I at $684.3 \mathrm{~nm}$, which is located close to the maximum of the fluorescence emission peak and was thus chosen for this study. The DOAS fit was carried out in the wavelength window $681.8-685.5 \mathrm{~nm}$, which is close to, but outside of the oxygen-B band. This spectral region exhibits features from other inelastic processes and weak water vapor absorption features, but to a much lesser extent than the region around the Fraunhofer $\mathrm{H} \alpha$ line.

The reference spectrum of chl-a fluorescence calculated according to Eq. (3) alone with the selected fit window is shown in the left panel of Fig. 2. In order to demonstrate the differential structure of the obtained reference spectrum within the selected fit window the reference spectrum before and after polynomial subtraction is shown in the right panels of Fig. 2.

As pointed above, we account in the selected fit window not only for the contribution of inelastic processes but also for the absorption by water vapor. Because water vapor cross-sections depend on temperature and pressure, we decided not to choose one absorption crosssection for a given temperature and pressure, but to calculate the reference spectrum for water vapor analogously to the reference spectra for inelastic processes. In particular, the reference spectrum for water vapor was calculated according to Eq. (3), where $I^{+}(\lambda)$ and $I^{-}(\lambda)$ are modeled radiances at the top of atmosphere calculated including and excluding the absorption by water vapor, respectively.

All reference spectra were determined using average conditions, namely the pressure, temperature, and water vapor profiles were set as default in the model for April and latitude of $45^{\circ}$, according to a climatological data base obtained using a 2D chemical transport model developed at the University of Bremen (Sinnhuber, Sheode, Sinnhuber, Chipperfield, \& Feng, 2009).

\subsection{Retrieval technique of chlorophyll fluorescence}

Using the information and setting described in the previous section, the DOAS algorithm used for the retrieval of chl-a fluorescence in the spectral window $681.8-685.5 \mathrm{~nm}$, which will be referred to hereafter as the $W_{F}$ spectral window, is formulated as follows:

$\left\|\tau(\lambda)-\sigma_{w}(\lambda) S_{w}-\sigma_{f}(\lambda) S_{e}-\sum_{k=0}^{K} a_{k} \lambda^{k}\right\|^{2} \rightarrow \min$,

where $\sigma_{w}(\lambda)$ and $S_{w}$ are the water vapor reference spectrum and scaling parameter, respectively, and $S_{e}$ is the effective scaling parameter of the fluorescence reference spectrum which accounts for the filling-in of the Fe I Fraunhofer line caused by all inelastic processes.

Despite the fact that water vapor is fitted in the fluorescence DOAS fit, numerous numerical experiments have shown that the retrieved fluorescence fit factors are still to some extent sensitive to changing water vapor concentrations. As our fluorescence retrieval is additionally sensitive to the Raman scattering, we decided to apply corrections for these processes. In order to estimate the influence of water vapor absorption and the contribution of Raman scattering, we performed two additional DOAS retrievals in spectral windows $688.0-700.0 \mathrm{~nm}$ and 615.9-620.9 nm, respectively. Hereafter these spectral windows will be referred to as the $W_{W}$ and $W_{R}$ spectral windows. We note that the $W_{W}$ spectral window has been used by Noël, Buchwitz, Bovensmann, and Burrows (2005) and Noël, Mieruch, Bovensmann, and Burrows (2008) to retrieve water vapor from SCIAMACHY. The locations of all the spectral windows are shown along with the example of a SCIAMACHY measurement in Fig. 3.

Performing the DOAS retrieval of the simulated data in the fluorescence, water vapor, and Raman scattering spectral windows for the different atmospheric scenarios and solar zenith angles, we have derived the correction scheme for the fluorescence fit factor. The specific corrections are explained in detail below. 

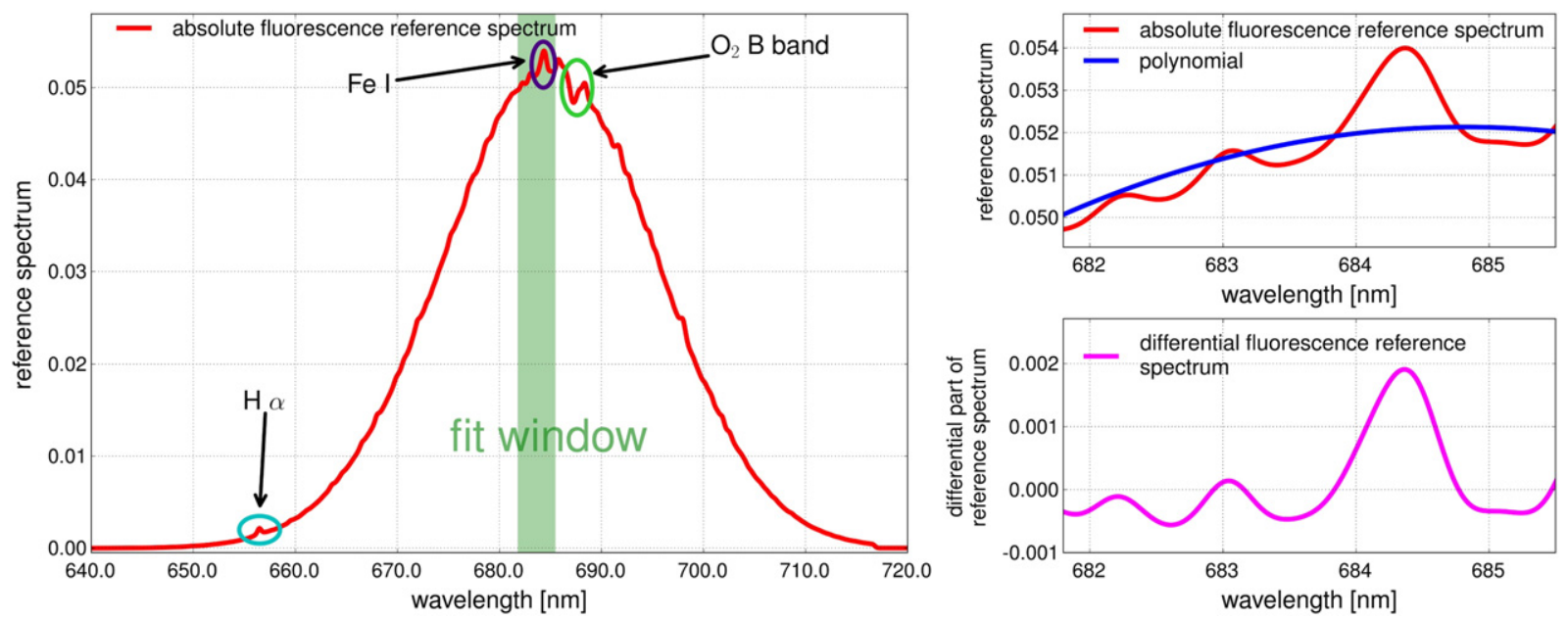

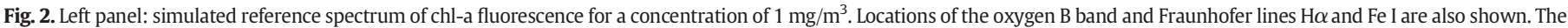

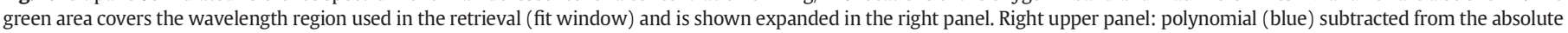
reference fluorescence spectrum (red). Right lower panel: the fluorescence differential fluorescence spectrum (magenta).

Reference spectra for all components involved in the DOAS fitting process were pre-calculated with high spectral resolution $(0.01 \mathrm{~nm})$. To account for the different spectral resolution of the instruments, the simulated spectra needed to be convolved with the appropriate slit function. We used a Gaussian type slit function, of which the full width at half maximum (FWHM) parameter was optimized with respect to the chi-square errors for each retrieval for a sample data set (odd days of January 2009). The process was done for each instrument separately (SCIAMACHY, GOME-2). Additionally, to account properly for the instrument resolution in the modeling, the simulated data of top of atmosphere radiances that were used for calculating corrections, were also convolved with a Gaussian type slit function. The FWHM functions used for convolving simulated radiances were $0.4 \mathrm{~nm}$ and $0.488 \mathrm{~nm}$ for SCIAMACHY and GOME-2, respectively, for the main fluorescence and water vapor correction retrievals; those values have already been used in other DOAS retrievals at the $W_{W}$ spectral window (Noël et al., 2005, 2008). For the Raman scattering simulations (important for further correction of our fluorescence results as detailed below), we convolved the radiances with a Gaussian of the FWHM of $0.3 \mathrm{~nm}$ for
SCIAMACHY and $0.4 \mathrm{~nm}$ for GOME-2. Those values were based on the difference between the optimized FWHM for reference spectra for fluorescence and the Raman scattering.

\subsubsection{Water vapor correction}

To obtain the water vapor correction, we used the uncoupled version of the radiative transfer model SCIATRAN. In this case we set the fluorescence emission in the $W_{F}$ window to a number of specific constant values at the surface and hence it was not further dependent on other environmental parameters such as solar zenith angle (SZA), chl-a absorption, light penetration depth, etc. The simulations were performed for the aerosol free atmosphere and the following scenarios:

- the water vapor vertical column was set to $0.1,1.0,2.0,3.0,4.0$, and $5.0\left[\mathrm{~g} \mathrm{~cm}^{-2}\right]$;

- fluorescence emission at the surface was set to $0.1,0.5,1.0$, and $2.0\left[\mathrm{~mW} \mathrm{~m}^{-2} \mathrm{sr}^{-1} \mathrm{~nm}^{-1}\right]$;

- SZA varied from $20^{\circ}$ to $70^{\circ}$ with $10^{\circ}$ step increments;

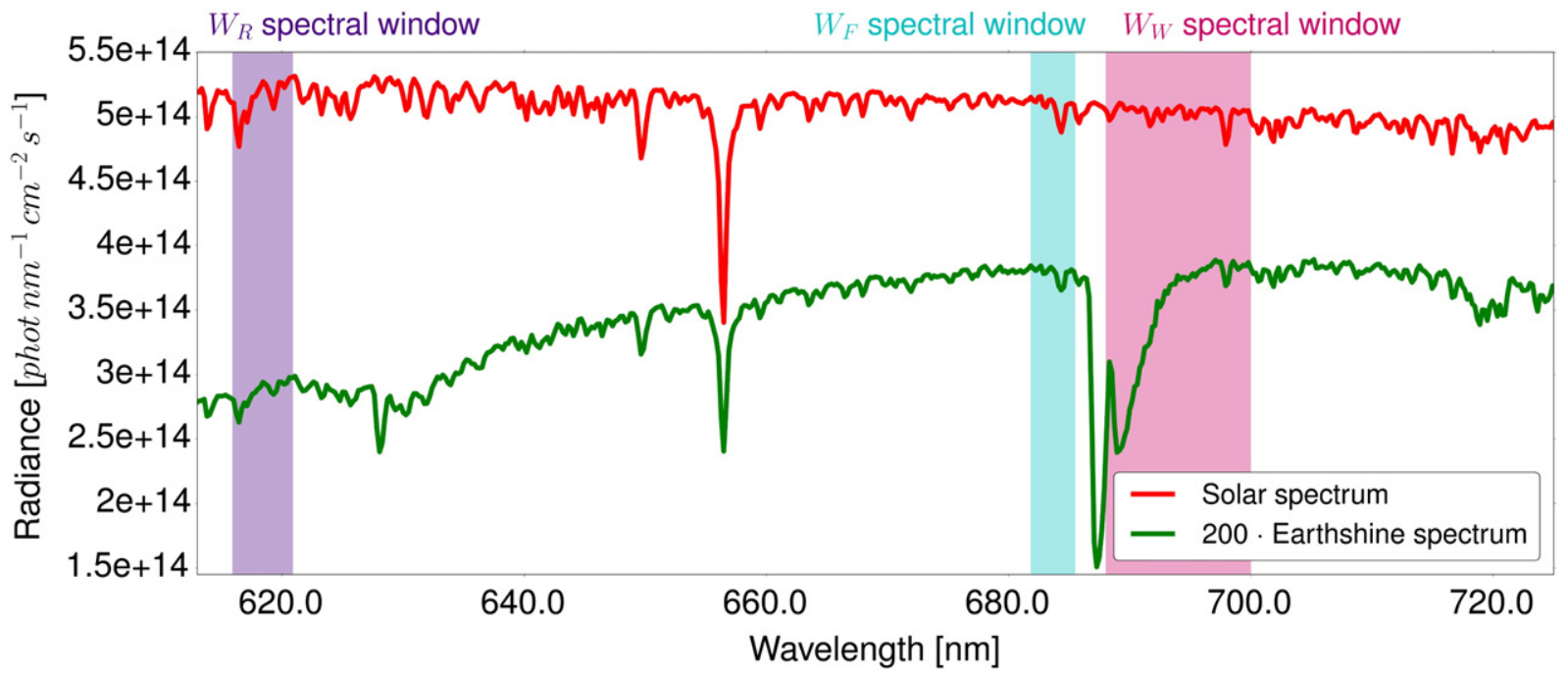

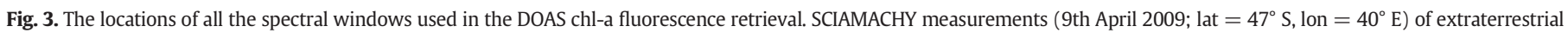
irradiance (red line) and scaled backscatter radiance (green) correspond to the sample DOAS shown further in Fig. 8. 
- the surface albedo was set to a constant value of 0.1 (following Noël et al., 2004).

The water vapor fit factors were obtained solving two following minimization problems:

$\left\|\tau(\lambda)-S_{w f} \sigma_{w}(\lambda)-\sigma_{f}(\lambda) S_{e}-\sum_{k=0}^{K} a_{k} \lambda^{k}\right\|^{2} \rightarrow \min , \quad W_{F} \in[681.8,685.5]$,

$\left\|\tau(\lambda)-S_{w w} \sigma_{w w}(\lambda)-S_{O_{2}} \sigma_{O_{2}}(\lambda)-\sum_{k=0}^{K} a_{k} \lambda^{k}\right\|^{2} \rightarrow \min , \quad W_{W} \in[688.0,700.0]$,

where $S_{w f}$ and $S_{w w}$ are the water vapor fit factors in $W_{F}$ and $W_{W}$ spectral windows, respectively, $\sigma_{w w}(\lambda)$ and $\sigma_{O_{2}}(\lambda)$ are reference spectra of the water vapor and $\mathrm{O}_{2}$-B absorption band in the $W_{W}$ window calculated in the same way as described above.

The results obtained show that the retrieved $S_{w f}$ values are much noisier than $S_{w w}$ because the water vapor absorption is smaller in the $W_{F}$ window. Moreover, the retrieved fluorescence fit factors are still sensitive to the variation of the water vapor concentrations. In order to mitigate the impact of water vapor on the fluorescence fit factors we used the following correction algorithm:

$\hat{S}_{e}=S_{e}-\Delta_{w w}$

where $\hat{S}_{e}$ is a corrected fluorescence fit factor. The function $\Delta_{w w}$ was calculated as a difference between the retrieved fluorescence fit factors $S_{f w}$ and $S_{f 0}$ obtained for the case of simulation with and without water vapor in the atmosphere, respectively. The function was described best in a least-squares sense by a second order polynomial:

$\Delta_{w w}=S_{f w}-S_{f 0}=0.0160 S_{w w}^{2}+0.0029 S_{w w}+0.0024$.

It can be seen that the introduced correction enables the obtained fluorescence fit factor to be extrapolated to the case of a water vapor free atmosphere using the retrieved water vapor fit factor $S_{w w}$. It follows from the left panel of Fig. 6 that the relationship between $\Delta_{w w}$ and $S_{w w}$ does not change significantly with respect to SZA (different angles were not highlighted) and chl-a fluorescence emission, even though water vapor and fluorescence fit factors themselves are dependent on these parameters. It should be noted that due to the weak dependence of the water vapor correction factor on the surface albedo we have used only a single albedo value for performing these radiative transfer simulations. This allows us to employ the same correction factor for the fluorescence retrieval over the ocean and land. We assume that this approximation is suitable in the framework of this feasibility study and can easily be improved in the future.

\subsubsection{Raman scattering correction}

In order to account for Raman scattering, we separate its contribution to filling-in of Fraunhofer lines from filling-in originating from fluorescence. The reference spectra of all inelastic scattering processes show similar spectral structures mirroring the spectral structures of the solar irradiance spectrum, even though within the broad spectral range they exhibit significant differences (Fig. 4). However, within a narrow spectral range, as used in this study, after polynomial subtraction they differ only by a scaling factor (Fig. 5). From the mathematical point of view this means that in the fluorescence fit window the Raman scattering reference spectrum can be represented by a scaled fluorescence reference spectrum, i.e.,

$\sigma_{R}(\lambda) \approx C \sigma_{f}(\lambda)$

It follows that the effective scaling parameter $S_{e}$ introduced in Eq. (5) can be represented as a linear combination

$S_{e}=S_{f}+C S_{R}$

Thus, to correct the impact of Raman scattering on the filling-in of the selected Fraunhofer line we need to estimate $C S_{R}$ and subtract it from the effective parameter $S_{e}$.

For this purpose, Raman scattering was retrieved in the $W_{R}$ window using the DOAS algorithm. This wavelength region is already outside, but it is still close to the fluorescence emission band. This assures that the relationship between the Raman scattering fit factors obtained in the $W_{R}$ and $W_{F}$ spectral windows does not change significantly with respect to atmospheric/aquatic conditions.

The model radiances at the top of the atmosphere were calculated including the rotational Raman scattering, but neglecting the water vapor absorption and fluorescence emissions. The DOAS fit can be

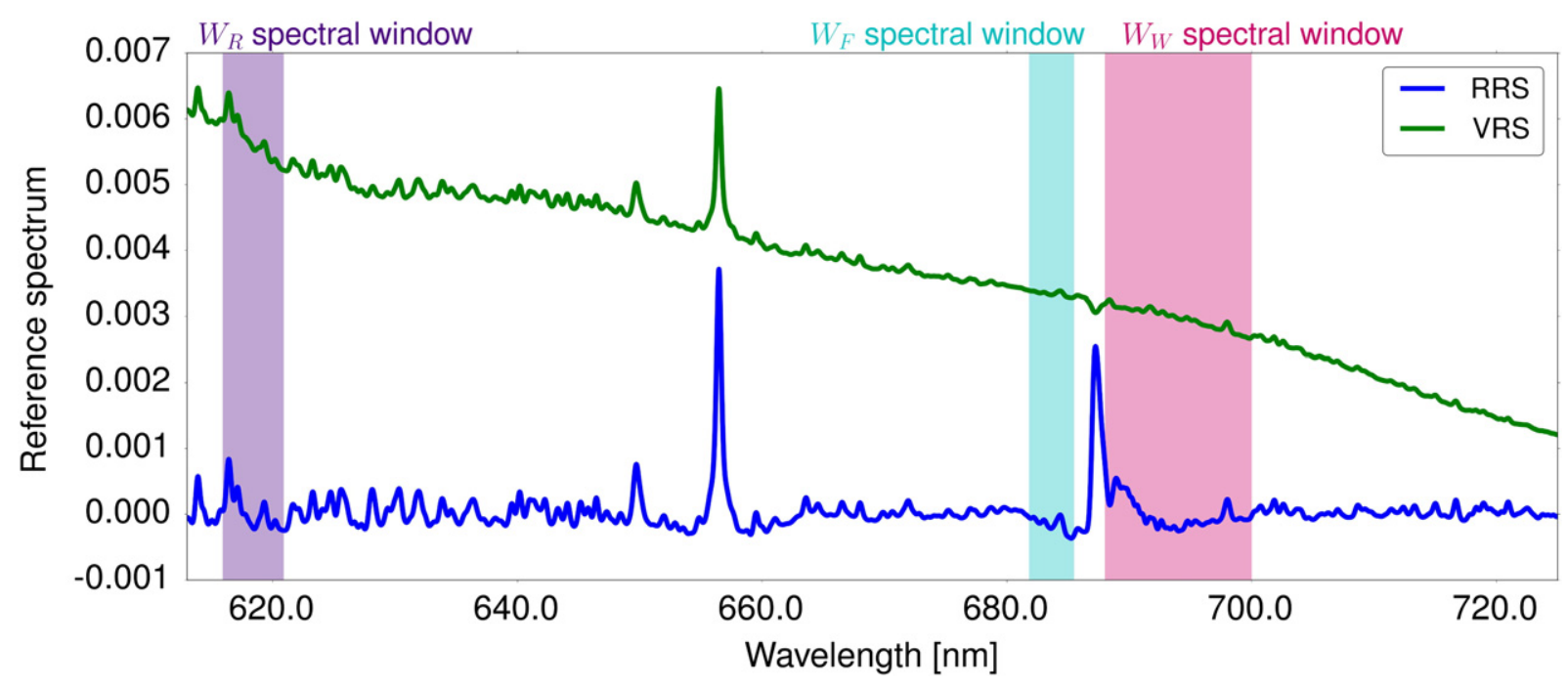

Fig. 4. Simulated reference spectra of RRS and VRS and the locations of all the spectral windows used in the DOAS chl-a fluorescence retrieval. 


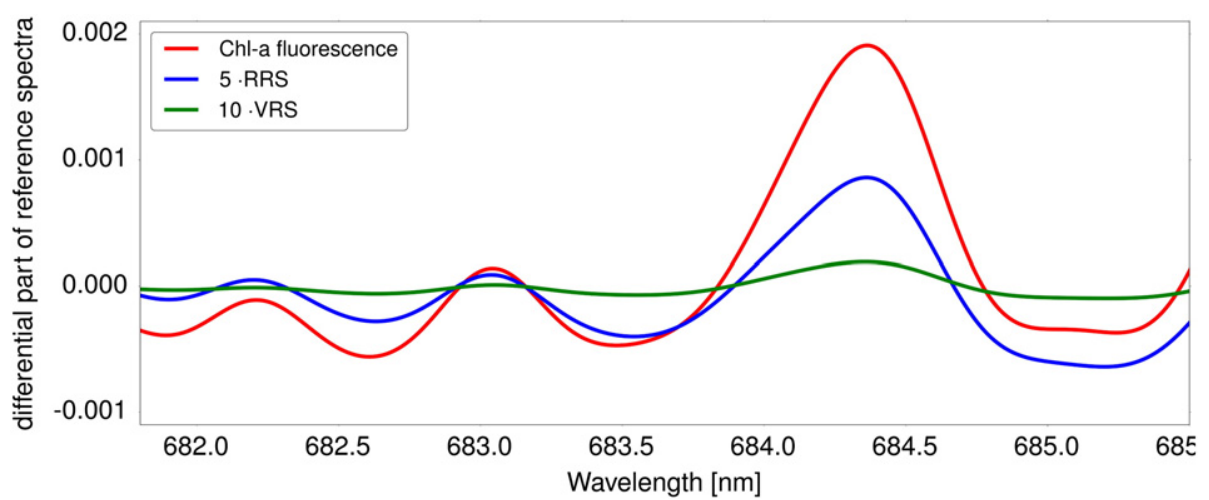

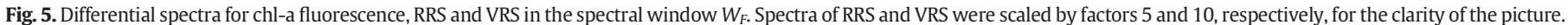

formulated under these assumptions in the form of two following minimization problems:

$$
\begin{aligned}
& \left\|\tau(\lambda)-\chi \sigma_{x}(\lambda)-\sum_{k=0}^{K} a_{k} \lambda^{k}\right\|^{2} \rightarrow \min , \quad W_{R} \in[615.9,620.9], \\
& \left\|\tau(\lambda)-y \sigma_{R}(\lambda)-\sum_{k=0}^{K} a_{k} \lambda^{k}\right\|^{2} \rightarrow \min , \quad W_{F} \in[681.8,685.5],
\end{aligned}
$$

where $\sigma_{x}(\lambda), x$ and $\sigma_{R}(\lambda), y$ are the Raman scattering reference spectra and fit factors from the $W_{R}$ and $W_{F}$ spectral windows, respectively.

The simulations of RRS were performed for the following atmospheric scenarios:

- aerosol optical thickness at $650 \mathrm{~nm}$ set to $0,0.05$, and 0.12;

- SZA varied from $20^{\circ}$ to $70^{\circ}$ with $5^{\circ}$ step increments;

- the surface albedo varied from 0.01 to 0.5 with 0.01 step increments.

Preliminary simulations showed that VRS leads to minor filling-in as compared to RRS, which can also be seen in the comparison of the amplitudes of their differential reference spectra (Fig. 5).

As a result, we modeled the impact of VRS for a limited set of conditions. VRS was modeled using the coupled version of SCIATRAN for the aerosol free atmosphere, the wind speed set to $5 \mathrm{~m} / \mathrm{s}$, and the following scenarios:

- chl-a concentration was set homogeneously to 0,1 and $10 \mathrm{mg} / \mathrm{m}^{3}$;

- SZA varied from $20^{\circ}$ to $70^{\circ}$ with $10^{\circ}$ step increments.

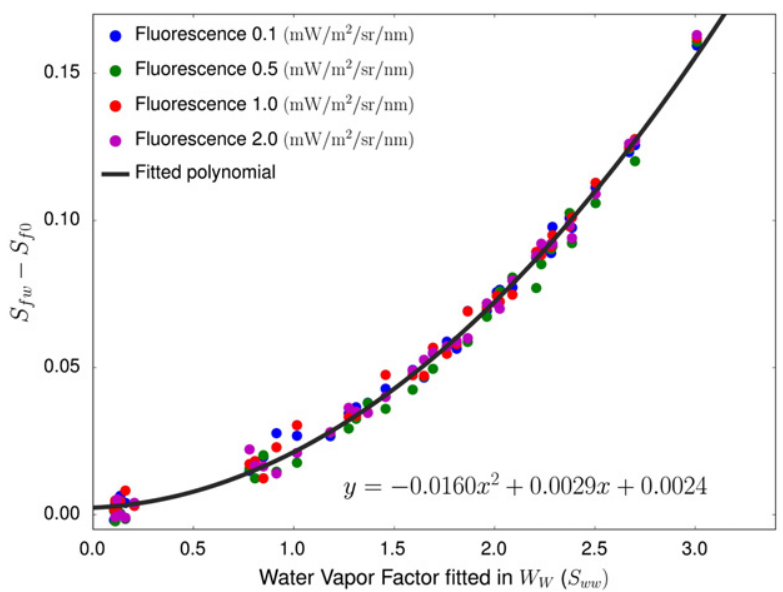

As expected, VRS leads to negligible filling-in, as compared to RRS. As a result we decided to calculate the correction based on RRS simulations only. Having solved the minimization problems given by Eqs. (12) and (13) for different SZAs, we have found that the relationship between RRS fit factors in both spectral windows can be represented in the form of the following regression:

$y=a\left(\vartheta_{0}\right) x^{2}+b\left(\vartheta_{0}\right) x+c\left(\vartheta_{0}\right)$,

where coefficients $a, b$ and $c$ depend slightly on SZA ( $a \in[0.0116,0.0182]$, $b \in[0.0701,0.0849]$, and $c \in[0.0138,0.0288])$.

A subset of these resulting relationships for three SZAs is shown in the right panel of Fig. 6 . The fit factor values determined from the Raman scattering fit in the $W_{R}$ window are subtracted from the retrieved fluorescence fit factors, according to the following equation:

$\widehat{\hat{S}}_{e}=\hat{S}_{e}-C(y)$,

where $\hat{S}_{e}$ is the fluorescence fit factor calculated according to Eq. (8), $C$ is the factor obtained by the scaling of the reference fluorescence spectrum according to Eq. (10); $y$ is calculated according to Eq. (14) for a given SZA of the measurement, and for SZAs not used in the simulations, we interpolate the $y$ value between the two nearest SZAs.

Taking the above corrections into account to remove the interference of water vapor and Raman scattering in filling of the Fraunhofer

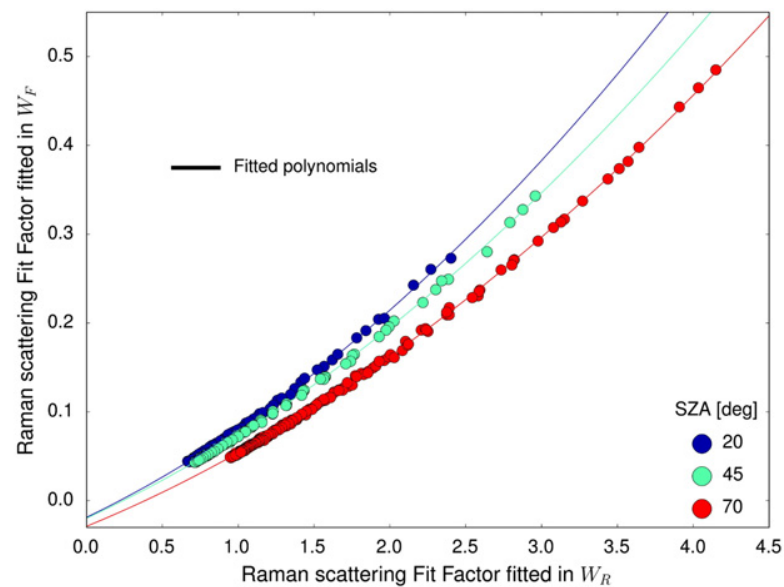


Fe I line in the $681.8 \mathrm{~nm}$ to $685.5 \mathrm{~nm}$ spectral window, the retrieved fluorescence emission fit factor $S_{f}$ is calculated as follows:

$$
\begin{aligned}
S_{f}= & S_{e}-\left(0.0160 S_{w w}^{2}+0.0029 S_{w w}+0.0024\right) \\
& -C\left[a\left(\vartheta_{0}\right) S_{R}^{2}+b\left(\vartheta_{0}\right) S_{R}+c\left(\vartheta_{0}\right)\right]
\end{aligned}
$$

where, the parameters $S_{e}, S_{w w}$, and $S_{R}$ are obtained performing multiwindow DOAS fit in the $W_{F}, W_{W}$, and $W_{R}$ spectral windows, respectively.

\subsubsection{Relationship between fluorescence fit factor and absolute emission spectrum}

The fluorescence DOAS fit factor $S_{f}$ obtained as a solution of the corresponding minimization problem is readily recalculated in the form of the absolute fluorescence emission spectrum. To demonstrate this, let us consider the fluorescence reference spectrum given by Eq. (3) and rewrite it in the following form:

$\sigma_{f}(\lambda)=\ln \frac{I^{+}(\lambda)}{I^{-}(\lambda)}=\ln \frac{I^{-}(\lambda)+\Delta I(\lambda)}{I^{-}(\lambda)} \approx \frac{\Delta I(\lambda)}{I^{-}(\lambda)}$,

where we have taken into account that the variation of radiance at the top of the atmosphere, $\Delta I(\lambda)$, caused by the fluorescence emission is much smaller than the elastic radiance, i.e., $\Delta I(\lambda) \ll I^{-}(\lambda)$. Assuming further that the a priori absolute fluorescence emission spectrum at the surface is $e_{a}(\lambda)$, we can write

$\Delta I(\lambda)=C_{a} e_{a}(\lambda)$,

where the factor $C_{a}$ depends on the environmental conditions, i.e., $I^{-}(\lambda)$.

Comparing Eqs. (17) and (18), we can state that for the elastic radiance $I^{-}(\lambda)$ :

$e(\lambda)=S_{f} e_{a}(\lambda)$,

i.e., the fluorescence DOAS fit factor $S_{f}$ is also the scaling factor of the $a$ priori absolute fluorescence emission spectrum; $e(\lambda)$ is then the resulting fluorescence emission spectrum at the surface.

The elastic scattering varies over an orbit and is not constant for the satellite measurements. As a result, the conversion from retrieved $S_{f}$ into fluorescence emission at the surface is a function of $I^{-}(\lambda)$. As explained in Section 2.1, and seen in Eq. (2), the polynomial carries the information about the background signal and broad-band effects. To address this issue, we developed a conversion scheme from $S_{f}$ to absolute fluorescence emission, which is dependent on the measured radiance, i.e., on the mean value of the polynomial fitted in the $W_{F}$ spectral window. In order to simulate a variety of atmospheric and surface conditions and hence different background radiances and different polynomials obtained in the DOAS fitting, the following simulations were performed for a water-vapor free and excluding RRS atmosphere:

- three atmosphere scenarios: no aerosols and Rayleigh optical thickness at $600 \mathrm{~nm}$ amounting to 0.07 or 0.1 ; aerosol optical thickness at $650 \mathrm{~nm}$ amounting to 0.3 with Rayleigh optical thickness at $600 \mathrm{~nm}$ amounting to 0.07 ;

- fluorescence emission at the surface varying from 0.01 to $5 \mathrm{~mW} \mathrm{~m}^{-2} \mathrm{sr}^{-1} \mathrm{~nm}^{-1}$ with $0.01 \mathrm{~mW} \mathrm{~m}^{-2} \mathrm{sr}^{-1} \mathrm{~nm}^{-1}$ step;

- SZA varying from $17^{\circ}$ to $70^{\circ}$ with $1^{\circ}$ step increments;

- the surface albedo varying from 0.01 to 0.5 with 0.01 step increments.

We have simulated top of atmosphere radiances for all the combinations of these parameters (4,050,000 combinations). The fluorescence retrieval was performed on simulated data for which the mean value of the polynomial fitted within the spectral window was calculated.

We have obtained that the relationship between the absolute fluorescence emission and the fluorescence fit factor $S_{f}$ can be represented in the following form:

$e=a S_{f}^{2}+b S_{f}+c$

where the polynomial coefficients depend on the mean radiance value, i.e., on the mean value of the polynomial fitted within the spectral window $W_{F}$. Coefficients $a, b$, and $c$ in Eq. (20) were calculated for the mean polynomial values between 2.2 and 5.4 with 0.01 step increments. A subset of these functions is shown in Fig 7. As we compare our results of marine chlorophyll fluorescence with MODIS data (see Section 3), we will call the resultant absolute fluorescence emission as fluorescence line height for SCIAMACHY (FLH) for the Fe I Fraunhofer line. The latter is given by:

$$
\mathrm{FLH}=S_{f} e_{a}\left(W_{F}\right)
$$

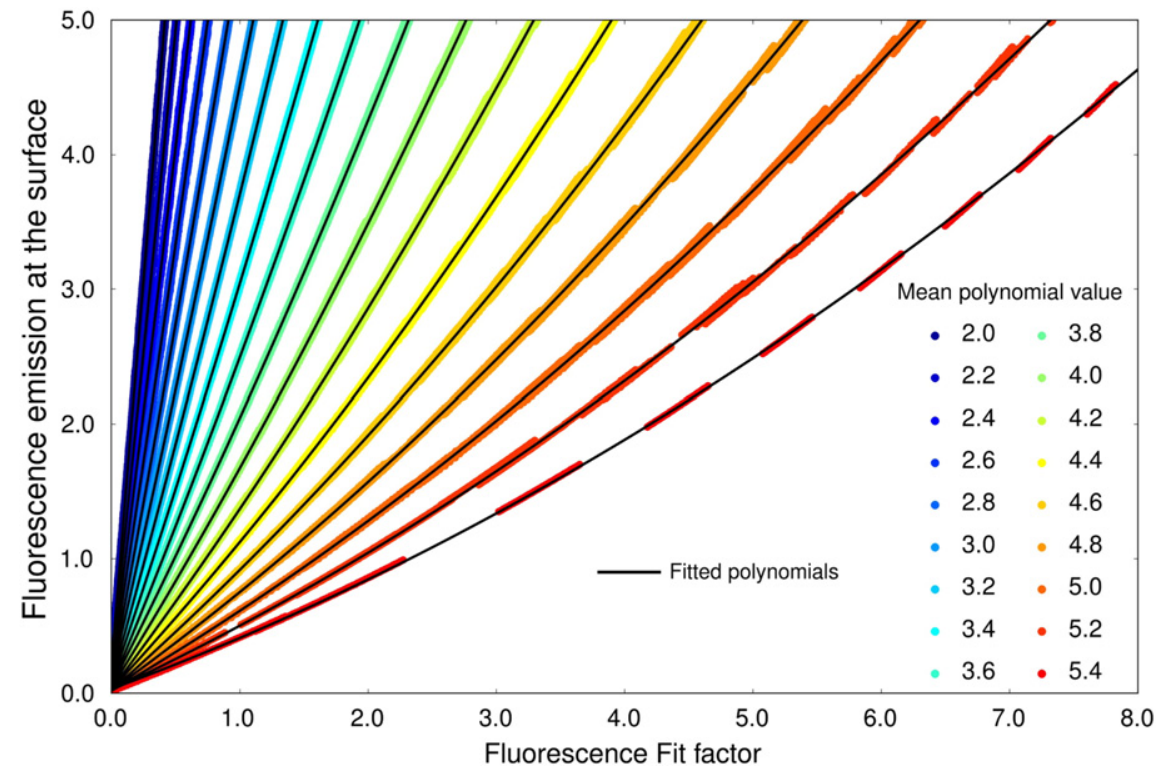

Fig. 7. Conversion scheme between retrieved fluorescence fit factors $S_{f}$ and the fluorescence emission at the surface, for a subset of calculated mean polynomial values. 


\subsection{Satellite data}

The retrieval was developed for and applied to SCIAMACHY data. In a second step it was also applied to data from GOME-2 in order to demonstrate its applicability to other sensors.

SCIAMACHY is a grating spectrometer measuring transmitted, reflected and scattered sunlight in three different viewing geometries: nadir, limb, and both solar and lunar occultations (Bovensmann et al, 1999; Burrows, Hölzle, Goede, Visser, \& Fricke, 1995). In addition, it measures solar irradiance. SCIAMACHY makes measurements of the upwelling radiation at the top of the atmosphere in nadir and in limb viewing geometry from 214 to $2380 \mathrm{~nm}$ in eight spectral channels, continuously from 214 to $1750 \mathrm{~nm}$ at relatively high resolution $(0.2 \mathrm{~nm}$ to $1.5 \mathrm{~nm})$. The channels with high spectral resolution have a variable ground scene footprint, which is typically $30 \mathrm{~km} \times 60 \mathrm{~km}$. The instrument was launched in February 2002 on board the ENVISAT satellite into a sun synchronous orbit in descending node having a 10:00 am equator crossing time. ENVISAT was in operation until April 2012 when ESA unexpectedly lost contact. Each nadir measurement is followed by a limb measurement, which leads to intermittent nadir scan along-track. The swath width for both measurement cycles is $960 \mathrm{~km}$. SCIAMACHY's main objective was to measure trace gasses in the atmosphere; however, part of the detected radiation is influenced by absorption and scattering from the surface layer of the ocean. This characteristic was already used to estimate vibrational Raman scattering by water and retrieve different phytoplankton groups (see above). In this study spectra from SCIAMACHY channel 4 are used.

GOME-2 are a series of three identical instruments operating from polar orbiting meteorological satellites MetOps (Callies, Corpaccioli, Eisinger, Hahne, \& Lefebvre, 2000; Munro et al., 2006). The data used here are from the first GOME-2, which was launched in October 2006 onboard MetOp-A, which, like ENVISAT, flies in a sun-synchronous orbit having an equator crossing time of 9:30 am. It measures the Earth's backscattered radiance and the solar irradiance at wavelengths between 232 and $793 \mathrm{~nm}$. In comparison to SCIAMACHY, GOME-2 has a larger footprint (40 km $\times 80 \mathrm{~km})$ and a large nominal scan swath width $(1920 \mathrm{~km})$, though approximately once a month a narrow swath mode ( $320 \mathrm{~km}$ ) is used. GOME-2 has near daily global coverage whereas SCIAMACHY, with its alternate limb and nadir viewing coupled with a swath width of $960 \mathrm{~km}$, achieves global coverage in only six days at the equator. Moreover, as the second GOME-2 onboard MetOp-B was launched in September 2012, from July 2013 onwards the MetOp-B/ GOME-2 instrument replaced the MetOp-A/GOME-2 in default swath mode, and MetOp-A/GOME-2 is now in a reduced swath mode, which means that swath is reduced to $960 \mathrm{~km}$ and pixel size is $40 \times 40 \mathrm{~km}$. The third satellite, MetOp-C, is scheduled for launch at the end of 2017.

Satellite observations included in the presented results were limited to SZA up to $70^{\circ}$. Cloudy ground scenes were removed by using a threshold reflectance, which was set empirically beforehand. Because detecting fluorescence is sensitive to clouds, the threshold was set to a very low value, which also removes ground scenes having large aerosol abundance, sun glint or glimmer, and very bright surfaces (e.g., Sahara and snow cover). The threshold was chosen to be relatively low for oceans ( 0.08 for SCIAMACHY and 0.075 for GOME-2) in order to remove the glint contaminated scenes.

For land, the value of the threshold selected was higher than that for ocean scenes ( 0.16 for SCIAMACHY and 0.15 for GOME-2). This is because the land has a higher surface reflectance than the ocean for the wavelength ranges used in this study. We also set a threshold for chisquare values below $10^{-5}$, and filtered out measurements that were assumed outliers (based on the standard deviations (std) of retrieved fluorescence emission from the mean value for the two-year results for SCIAMACHY or yearly results for GOME-2: data included were $\leq 5$ std).

\section{Results and discussion}

The DOAS method, described in detail in Section 2, was applied to SCIAMACHY data for the years 2003-2011. Although our retrieval was designed for SCIAMACHY and for the marine realm, it was subsequently also applied to GOME-2 data for the year 2009, and to land areas for July and December 2009 for both SCIAMACHY and GOME-2.

\subsection{Observations of marine fluorescence with SCIAMACHY}

An example of the spectral fits of the SCIAMACHY measurement over the ocean corresponding to one of the smallest chi-square values is shown in Fig. 8 (the SCIAMACHY measurements of extraterrestrial irradiance and backscatter radiance for the same scene are shown in Fig. 3). It follows that the measured differential optical depth (DOD) contains spectral structures of fluorescence (upper right panel) and water vapor (upper left panel) and those are successfully discriminated. The top panels of Fig. 8 clearly show that the residuals of the fit are very low $(\sim 0.02 \%)$. This indicates that there are no strong unidentified features in the selected spectral window and this provides an additional evidence for the validity of our retrieval.

The global yearly composite average of the marine phytoplankton fluorescence retrieved from SCIAMACHY for years 2003-2011 and separately for year 2009 are presented in Fig. 9a. The data points were gridded in $0.5^{\circ}$ by $0.5^{\circ}$ boxes. The SCIAMACHY results are presented in the form of FLH as defined by Eq. (21). Chlorophyll a concentrations from MODIS Terra (http://oceancolor.gsfc.nasa.gov/cgi/l3) for the same years are shown in Fig. 9d. It is important to point out that the SCIAMACHY FLH is the fluorescence energy retrieved in the Fe-I Fraunhofer band in the spectral window $681.8 \mathrm{~nm}$ to $685.5 \mathrm{~nm}$ whereas the MODIS nFLH is the difference between the spectral band $L_{14}$ and the mean of $L_{13}$ and $L_{15}$. Thus the tow retrievals are measuring fluorescence in different ways and in different, but overlapping, spectral windows. It is therefore not expected that the amount of energy determined by the two techniques is identical.

In general, we observe strong fluorescence signals in areas of high chlorophyll concentration, although the relationship is not thought to be constant (Behrenfeld et al., 2009 and references therein). The highest fluorescence values are observed in the North Atlantic and Pacific and in many coastal areas. Because of the coarse spatial resolution of SCIAMACHY data, small areas of high fluorescence very close to the shore are averaged across the larger scene and thus not well observed. For larger coastal regions (e.g., Persian Gulf and the upwelling regions along the west coast of Africa) high fluorescence values are derived, but not for narrow marine regions, such as the Gulf of Ob (Northern Russia).

The interannual variability is also observed readily in the SCIAMACHY FLH data, e.g., stronger phytoplankton blooms at the coast of Antarctica, which are observed in 2009 in MODIS Terra chla maps, are clearly noticeable in SCIAMACHY FLH results. Some values in the Atlantic east of Brazil are attributed to instrumental noise from the passage of the instruments through the South Atlantic Anomaly. This effect is also visible in the chi-square values of SCIAMACHY (Fig. 10a).

It is important to note, when comparing the yearly global composites, that at high-latitude areas ground scenes for fluorescence are only available for a limited time of the year. Areas, which are covered by ice or clouds during some period in the year, are biased to the cloud or ice free period (e.g., Indian monsoon region, which is mostly cloudy during the summer monsoon season). In Fig. 11 we present the number of data points of our retrieval per grid pixel. The number of points is inversely proportional to the global cloud fraction (during daytime only) product from MODIS. Very cloudy regions are poorlysampled and in high latitudes we are additionally limited by the high solar zenith angle. Because of the large pixel size and limb-nadir 

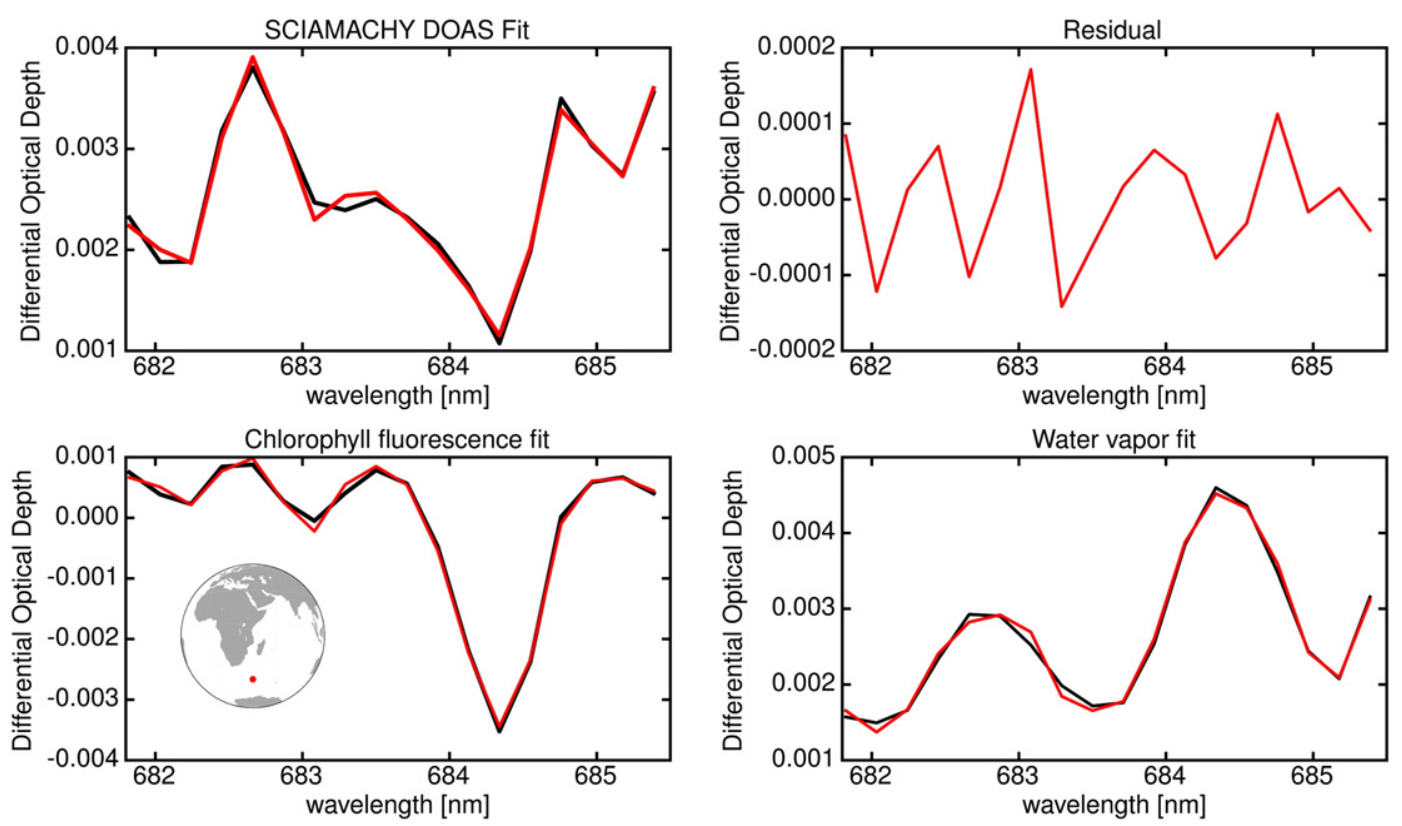

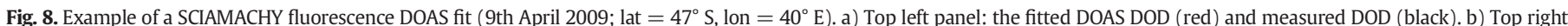

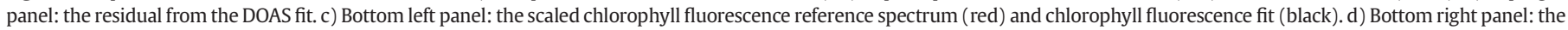
scaled water vapor reference spectrum (red) and water vapor fit (black).

mode of SCIAMACHY, less cloud and ice free scenes are available as compared to multispectral sensors with higher spatial resolution.

\subsection{Comparison with MODIS nFLH data}

The SCIAMACHY FLH data should be verified by performing comparisons with independent measurements of sun-induced chlorophyll fluorescence. Both MERIS and MODIS instruments provide measurements in spectral bands designed to map the chlorophyll fluorescence signal (Gower \& King, 2012).

Mapped MODIS nFLH data are easily available from the web (http:// oceandata.sci.gsfc.nasa.gov/), whereas MERIS data need to be derived from the Level 1 product. Hence, we decided to us MODIS data, as it was shown that MODIS and MERIS measurements of fluorescence closely agree (Gower \& King, 2004). In particular, we compared SCIAMACHY results to a MODIS Terra Level 3 standard nFLH product (http:// oceancolor.gsfc.nasa.gov/cgi/l3). Although for such comparison the MODIS Aqua data can also be used, and we gave preference to MODIS Terra because the time of MODIS Terra overpass is similar to SCIAMACHY $(\sim 10.00$ local time for ENVISAT; $\sim 10.30$ and $\sim 13.30$ for Terra and Aqua, respectively). We note that the different overpass times of satellites impact the retrieved fluorescence values, as the fluorescence increases as photochemistry saturates.

The standard MODIS product is available in the form of $\mathrm{nFLH}$. We remind the reader that according to Gordon and Voss (2004) and Gordon and Clark (1981) the following relationship between nFLH and FLH can be easily derived:

$\mathrm{nFLH}=\mathrm{FLH} \frac{F_{0}\left(\lambda_{14}\right)}{E_{d}\left(0^{+}, \lambda_{14}\right)}$.

Here, $F_{0}\left(\lambda_{14}\right)$ is the solar irradiance at the top of the atmosphere and $E_{d}\left(0^{+}, \lambda_{14}\right)$ is downwelling irradiance just above the surface, both measured in MODIS band 14. It follows that the quantitative comparison requires the calculation of $E_{d}\left(0^{+}, \lambda_{14}\right)$, which depends on the aerosol optical thickness and solar zenith angle among others. $E_{d}\left(0^{+}, \lambda_{14}\right)$ can be calculated running any coupled ocean-atmosphere radiative transfer model. However, this is a very time-consuming process requiring the global information of all atmospheric and oceanic parameters. Vice versa, the MODIS Terra Level 1 data (http://oceandata.sci.gsfc.nasa. gov/MODIST/L1/) in combination with SeaDAS software (http:// oceancolor.gsfc.nasa.gov/seadas/) can be used to calculate MODIS FLH for each single measurement point. However, to obtain yearly composite average values, which are needed for comparison, a very large number of MODIS Level 1 data has to be reprocessed.

In order to estimate the expected quantitative relationship between FLH and nFLH representation of fluorescence emission, we compared measurements for an arbitrary chosen day (20th January 2009) of MODIS Terra FLH and nFLH. For this purpose the Level 1 data were downloaded and processed with SeaDAS software. The default setting for atmospheric corrections and standard flags as in the Level $3 \mathrm{nFLH}$ product were used. The obtained results show that nFLH values are on average 1.5 times larger than FLH. However, they are up to four times different for low FLH values and the highest solar zenith angles.

Having this in mind, we decided to present our results also in the form of a simplified nFLH ( $\mathrm{snFLH}$ ), in which case we could at least account for the SZA dependence. Hence, we define snFLH for the purpose of this study, as follows:

$\operatorname{snFLH}=\mathrm{FLH} \frac{F_{0}\left(W_{F}\right)}{E_{d, s}\left(0^{+}, W_{F}\right)}$.

where $E_{d, s}\left(0^{+} W_{F}\right)$ is a simplified downwelling radiance, calculated with the SCIATRAN radiative transfer model with $F_{0}\left(W_{F}\right)$ as extraterrestrial irradiance, in the wavelengths of fluorescence fit window $W_{F}$. We call it simplified, as we account only for changes in the SZA. Considering that the main goal of our case study is to demonstrate the applicability of the DOAS approach to derive information about chlorophyll fluorescence, we restricted ourselves with the qualitative comparison of SCIAMACHY FLH and snFLH with MODIS nFLH data. For snFLH calculations, the aerosol optical thickness $\tau_{a}$ and Rayleigh optical thickness $\tau_{R}$ were set to constant values for all scenarios ( $\tau_{R}$ was set to 0.04 , following Bodhaine, Wood, Dutton, and Slusser (1999) and $\tau_{a}$ was set to 0.05 after Halthore and Caffrey (2006)). Halthore and Caffrey (2006) investigated $\tau_{a}$ at remote Pacific Ocean locations, and found a minimum $\tau_{a}$ of 0.017 at $670 \mathrm{~nm}$ for the Coconut Island measurements. However, for most presented measurements, the common values was $\sim 0.05$, and this value was chosen for this study. The aerosol distribution varies 
2009

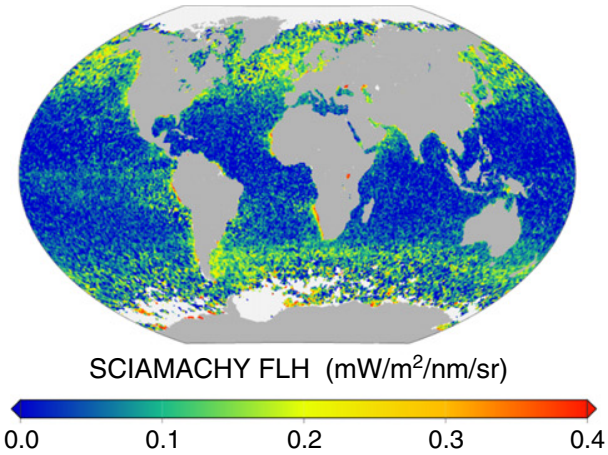

(a) SCIAMACHY FLH for years 2009 (left) and for years 2003-2011 (right)

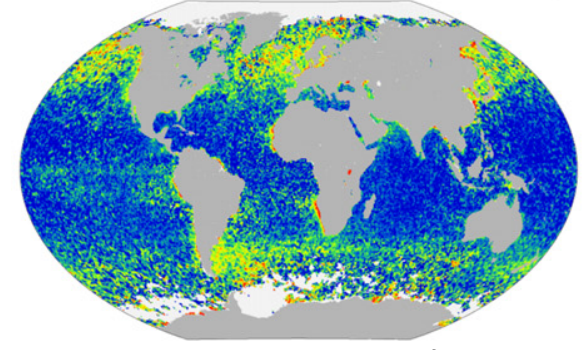

SCIAMACHY SnFLH $\left(\mathrm{mW} / \mathrm{m}^{2} / \mathrm{nm} / \mathrm{sr}\right)$

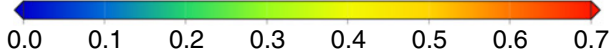

(b) SCIAMACHY snFLH for years 2009

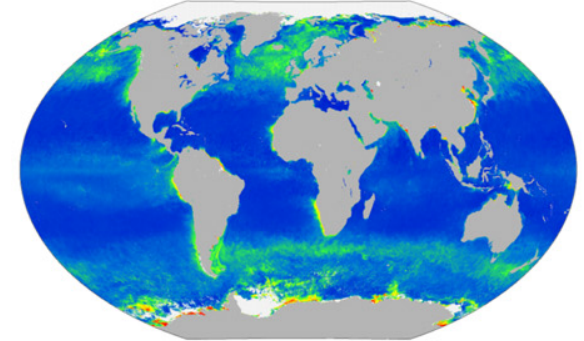

MODIS-Terra $\mathrm{nFLH}\left(\mathrm{mW} / \mathrm{m}^{2} / \mathrm{nm} / \mathrm{sr}\right)$

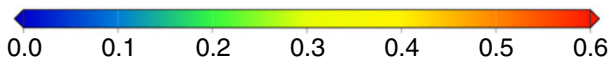

(c) MODIS nFLH for years 2009 (left) and for years 2003-2011 (right)

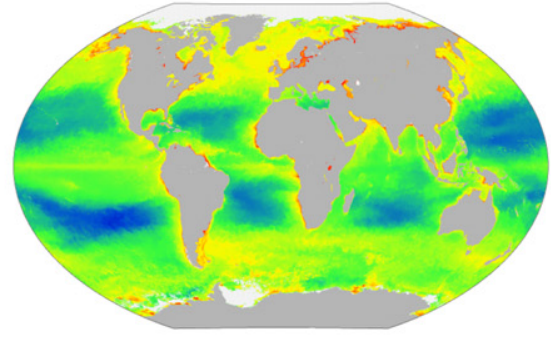

MODIS-Terra Chlorophyll a concentration $\left(\mathrm{mg} / \mathrm{m}^{3}\right)$
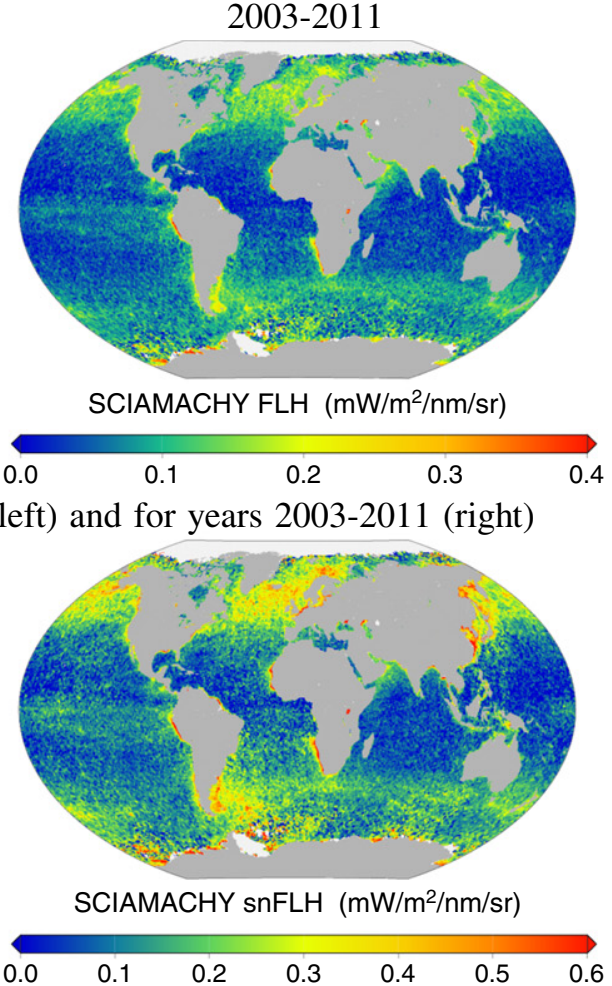

$\begin{array}{lllllll}0.0 & 0.1 & 0.2 & 0.3 & 0.4 & 0.5 & 0.6\end{array}$

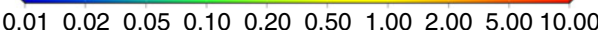

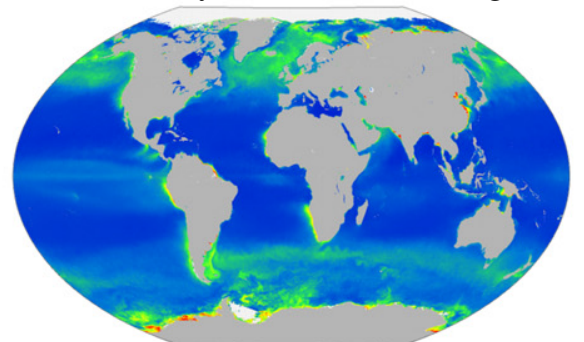

MODIS-Terra $\mathrm{nFLH}\left(\mathrm{mW} / \mathrm{m}^{2} / \mathrm{nm} / \mathrm{sr}\right)$

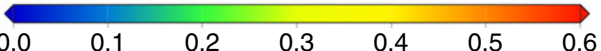

(d) MODIS chlorophyll a concentration for year 2009 (left) and for years 2003-2011 (right)

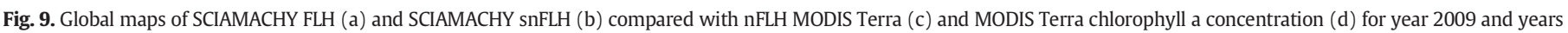
2003-2011.

over oceans, and is highest in the Atlantic Ocean next to Sahara, the Arabian Sea and the Bay of Bengal. However, in this study we focused solely on SZA dependency. For these SCIATRAN calculations, we used the Bidirectional Reflectance Distribution Function as surface reflection type, and set the wind speed to $5 \mathrm{~m} / \mathrm{s}$.
The yearly composite average nFLH values from MODIS Terra for the years 2003-2011 and year 2009 are presented in Fig. 9c. Comparing these data to the SCIAMACHY FLH and snFLH values presented in Fig. 9a and b, one can see a good spatial agreement between both data sets. 

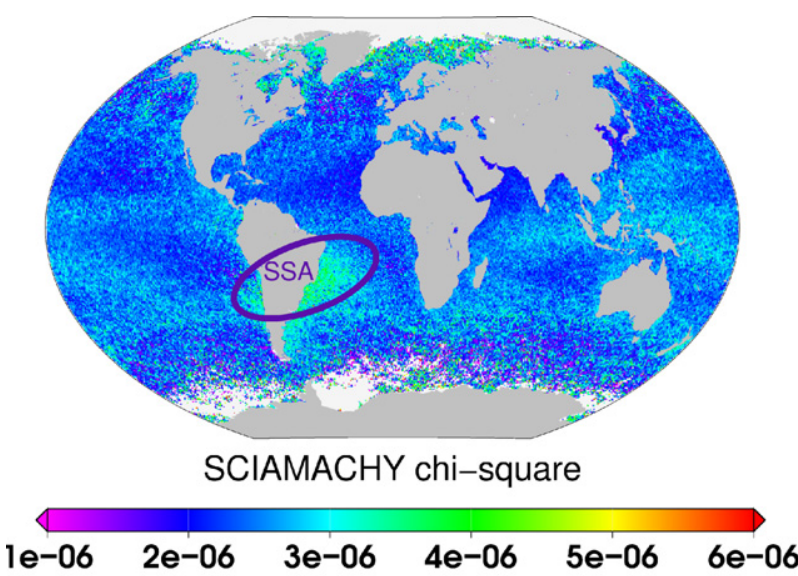

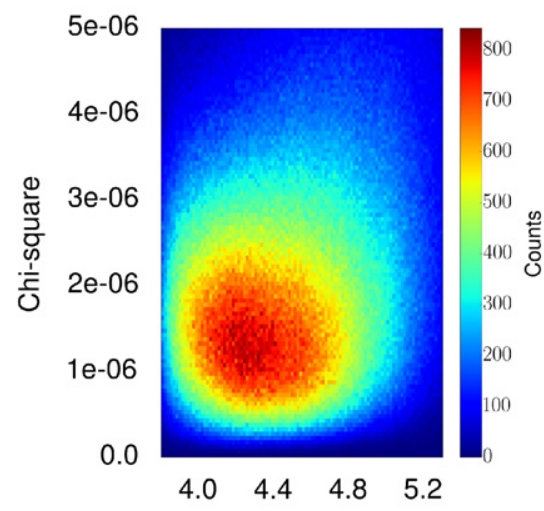

Mean polynomial value

(a) SCIAMACHY chi-square values for year 2009
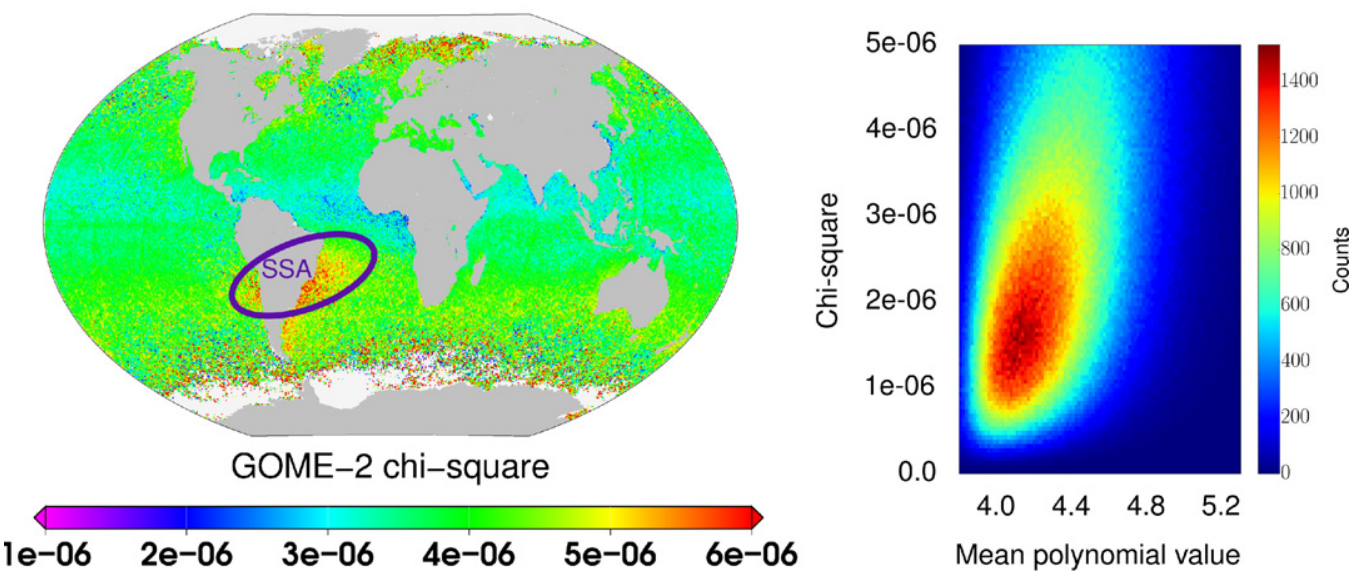

(b) GOME-2 chi-square values for year 2009

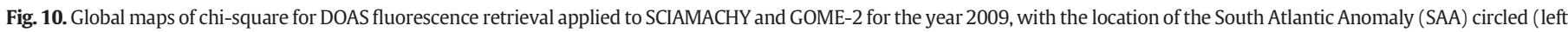
panel).

After applying simplified normalization, we observe that the values of SCIAMACHY snFLH are higher than SCIAMACHY FLH, especially snFLH close to the Antarctic coast is much more pronounced, and equatorial values are smaller as compared to high latitudes.

However, SCIAMACHY snFLH values are also higher than MODIS $\mathrm{nFLH}$. It is expected as our retrieval spectral window is placed exactly at the top of fluorescence emission, as opposed to the MODIS algorithm. The measured MODIS nFLH responds to only $57 \%$ of the actual fluorescence signal (Gower et al., 2004), as discussed in Section 1. Another possible reason of observed discrepancies can be the overestimated $\tau_{a}$, used for calculating $E_{d, s}\left(0^{+} W_{F}\right)$. The slightly earlier time of overpass of SCIAMACHY can also lead to different values.

It is important to note that after applying all corrections we obtained some negative values for SCIAMACHY. These negative values can be caused by random noise (especially in cases close to the fluorescence detection limit) and when the applied corrections (for water vapor and Raman scattering) are overestimated (see Eq. (16)). Negative values also occur for the MODIS nFLH algorithm, where they are removed assuming bad atmospheric correction or cloud contamination (Behrenfeld et al., 2009). However, in a recent study it was suggested
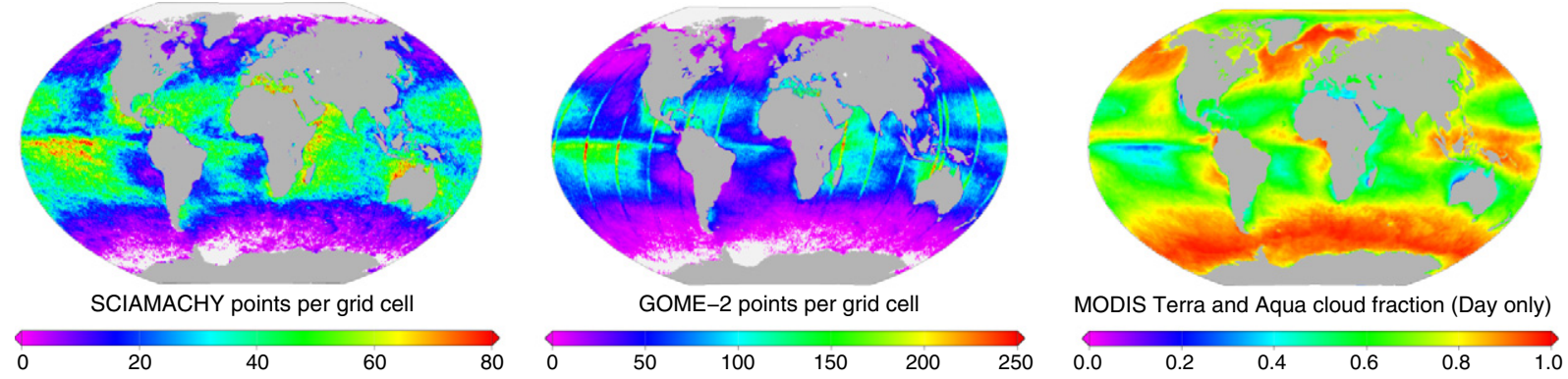

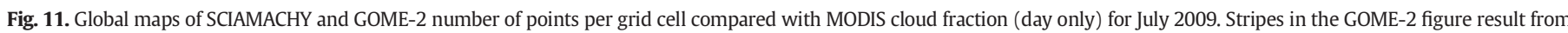
measurements made with the narrow swath mode. 
that the negative values represent a normal distribution of the data and arise from noise in the sensor, as they were found to constitute an increasing part of pixels with decreasing chlorophyll concentration (Huot et al., 2013). Following this recommendation we have included negative fit values in the averages, except for measurements which were removed by the quality checks. Nevertheless, excluding negative values does not significantly change the results presented in Fig. 9a and $\mathrm{b}$.

Comparing the multispectral MODIS and hyperspectral DOAS results, one has to keep in mind that the position of spectral bands used in the MODIS fluorescence retrieval algorithm reflects an assumed spectral shape of fluorescence. In particular, the fluorescence band is centered at $678 \mathrm{~nm}$ near the maximum of the fluorescence signal located at $685 \mathrm{~nm}$ (see Section 1). However, as shown by Gitelson (1992) and Xing et al. (2007) the apparent peak in the water leaving radiance is shifted toward longer wavelengths with increasing chlorophyll concentration, due to the strong chlorophyll absorption of red wavelengths (and re-absorption of chlorophyll fluorescence). The impact of this shift on nFLH is discussed by Gower and King (2004), who suggested that for retrieving chlorophyll fluorescence at high chlorophyll concentrations the measurements at longer wavelengths should be used additionally. Moreover, owing to the differences in light harvesting systems (pigment-protein binding in particular), especially in dinoflagellates and cyanobacteria (see MacIntyre et al., 2010; Millie, Schofield, Kirkpatrick, Johnsen, \& Evens, 2002), the peak wavelength of fluorescence depends also on the species composition of phytoplankton. Thus, for example, phycocyanin-rich cyanobacteria have an additional emission peak at $\sim 655 \mathrm{~nm}$ due to phycocyanin (MacIntyre et al., 2010; Simis, Huot, Babin, Seppälä, \& Metsamaa, 2012), which is close to the first chosen baseline for the MODIS algorithm $(667 \mathrm{~nm})$. Therefore, in the case of multispectral retrievals the position of spectral bands for the nFLH retrieval can lead to a smaller sensitivity and lower fluorescence values. It was also noted that during blooms of some cyanobacteria species the fluorescence signal is overwhelmed by scattering at longer wavelengths (peaks at 700-710 nm), which can lead to negative values of nFLH (Wynne et al., 2008). Hence, a computational equivalent to the negative values of MODIS nFLH has been used to detect cyanobacteria blooms in Lake Erie, first with MERIS (Wynne, Stumpf, Tomlinson, et al., 2013) and then with MODIS data (Wynne, Stumpf and Briggs, 2013).

In contrast to the multispectral retrieval, the hyperspectral method presented here uses a narrow spectral window for detecting the fluorescence emission, and subtracts a polynomial from the reference spectrum of fluorescence to account for broad-band features. The shape of the whole fluorescence emission band, and especially the apparent position of the fluorescence peak, is not relevant for the algorithm. It was demonstrated for terrestrial vegetation fluorescence retrievals using satellite hyperspectral data, that small changes in the fluorescence emission spectrum have indeed little impact on the estimated fluorescence values (Fournier et al., 2012; Joiner et al., 2013).

\subsection{Temporal variations in SCIAMACHY marine chl-a fluorescence}

As an example of a possible application for open ocean waters, we present time series of monthly SCIAMACHY FLH values averaged over two regions, in comparison to other satellite products and climate variables.

Firstly, the region in the Indian Ocean near the coast of Madagascar exhibits low chl-a concentrations $\left(<0.1 \mathrm{mg} / \mathrm{m}^{3}\right.$, shown as MODIS chl-a in Fig. 12 a), as it is located in the oligotrophic waters of the Indian Gyre. A seasonal cycle typical for all ocean gyres is observed, for which the common forcing factor is the change in surface thermal forcing that stimulates shallowing of mixed layers and increase of dynamic heights within the gyres. The higher dynamic height indicates strengthening of the gyre circulation and consequently promotes the deepening of thermocline/nutricline, which combined with shallower mixed layer depths, reduces the transport of nutrients to the euphotic zone. As a result, chl-a is reduced during the austral summer, and the opposite occurs for the austral winter cooling period (Signorini \& McClain, 2007, 2012). On top of this clear seasonal cycle, for most of the years, we observe the additional impact of the Madagascar bloom. It occurs typically early in the year and then spreads eastward for the next weeks, creating a feature called a plankton wave (Srokosz, 2004). This feature is one of the largest phytoplankton blooms in the world ocean, and has received much attention in the recent years (e.g., Huhn, von Kameke, Pérez-Muñuzuri, Olascoaga, \& Beron-Vera, 2012; Lévy et al., 2007; Longhurst, 2001; Raj, Peter, \& Pushpadas, 2010; Srokosz, 2004; Srokosz \& Quartly, 2013; Uz, 2007). Interannual variability of this phytoplankton bloom is linked to the upwelling along the south coast of Madagascar, precipitation along the east coast of Madagascar, light limitation and local mesoscale circulation features (Raj et al., 2010). The time series of SCIAMACHY FLH and MODIS nFLH follow for most parts the variability of MODIS chl-a concentration. Correlation coefficients between the three parameters are high (similar for SCIAMACHY FLH and MODIS nFLH to MODIS chl-a: 0.75 and 0.74 , respectively, and weaker between the two fluorescence variables). SCIAMACHY FLH values for this region indicate robustness of the retrieval, because both features, the seasonal cycle and the plankton wave, can be observed.

We present a second time series for the equatorial Pacific region, for which El Niño/Southern Oscillation (ENSO) is the dominant source of interannual climate variability (Fig. 12 b). During 'normal' or La Niña conditions, the Pacific equatorial ecosystem is productive due to the supply of nutrients to the euphotic zone in the cold tongue of waters upwelled in the eastern equatorial Pacific and stretching westward to the date line (Wyrtki, 1981). During El Niño conditions, physical forcing dramatically reduces phytoplankton productivity, impacting food webs across the equatorial and coastal environments of the eastern tropical Pacific (e.g., Barber \& Chavez, 1983; Barber \& Chávez, 1986; Chavez et al., 1999; Ryan, Polito, Strutton, \& Chavez, 2002; Strutton \& Chavez, 2000; Strutton, Evans, \& Chavez, 2008). ENSO can be monitored with the Multivariate ENSO Index (MEI), which is based on the climate variables observed over the tropical Pacific (Wolter \& Timlin, 1998). The MEI is positive in the El Niño phase and negative in the La Niña phase (data available at NOAA Earth Systems Research Laboratory http:// www.esrl.noaa.gov/psd/enso/mei/). The evident link between biology and the physical environment related to climate variability expressed by MEI has been shown for the Equatorial Pacific in the study by Rousseaux and Gregg (2012). In our case, we can also observe high correlations between monthly anomalies of SCIAMACHY FLH and MEI and MODIS sea surface temperature product (MODIS SST) (Fig. 12b and Table 1). MODIS SST data used in this study were produced with the Giovanni online data system, developed and maintained by the NASA GES DISC. SST is one of the input variables for calculating MEI and is directly related to the upwelling conditions. MODIS FLH and chl-a products are also significantly correlated to MEI and MODIS SST (Table 1). In essence, using SCIAMACHY fluorescence data we can observe seasonal variability in the phytoplankton community and its response to climate fluctuations for the equatorial Pacific.

\subsection{Observations of marine fluorescence with GOME-2}

The fluorescence signal from oceans was also retrieved with the GOME-2 onboard MetOp-A instrument for the year 2009 (Fig. 13). MetOp-A has a slightly earlier overpass time than ENVISAT, 9:30 am. As a result the solar zenith angle of the ground scene is larger for GOME-2 than for SCIAMACHY and the observed fluorescence signal is expected to be weaker. The regions of strong fluorescence are readily retrieved from the measurements of both sensors, but it is noticeable that the negative values are more frequent for the GOME- 2 results. This is attributed to the smaller fluorescence signal associated with higher SZA and the fact that the slit function is broader for GOME- 2 than for 


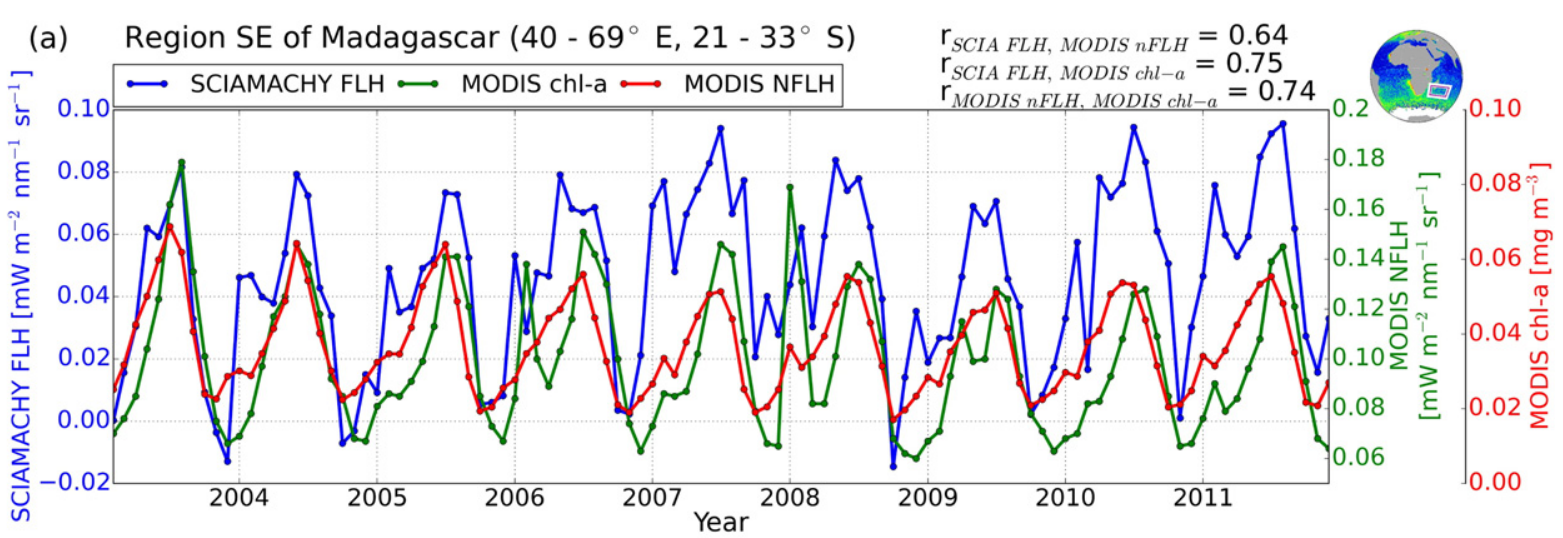

(b) Upwelling region in the Equatorial Pacific $\left(85-155^{\circ} \mathrm{W}, 2^{\circ} \mathrm{S}-6^{\circ} \mathrm{N}\right)$

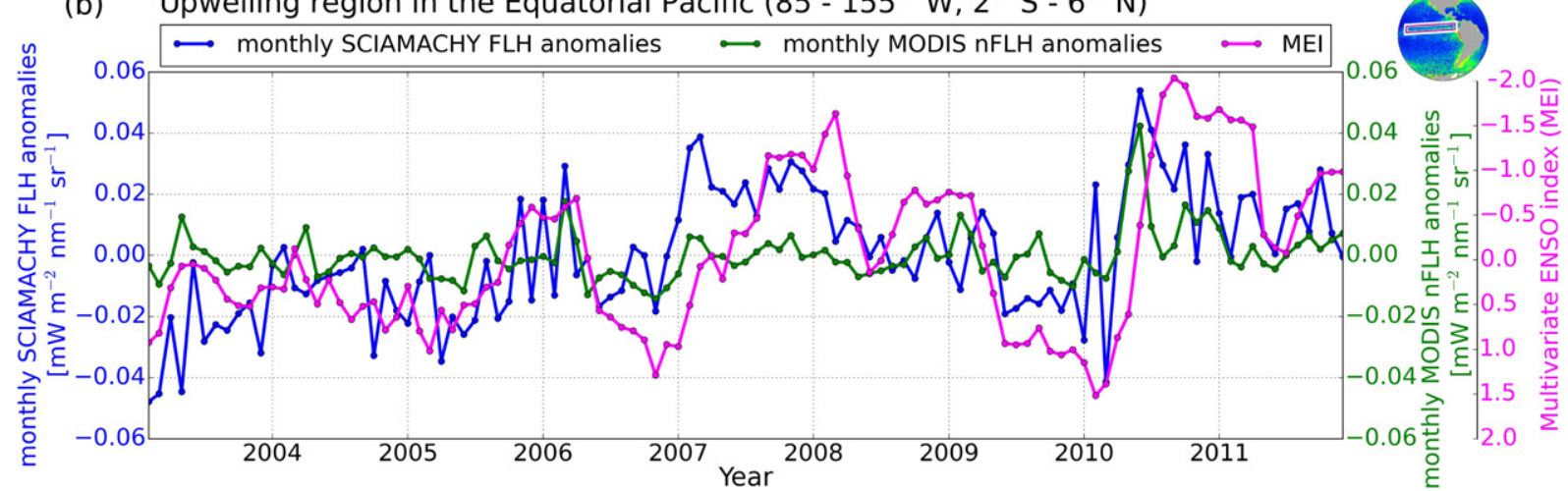

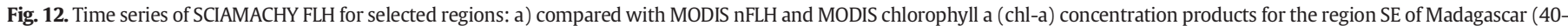

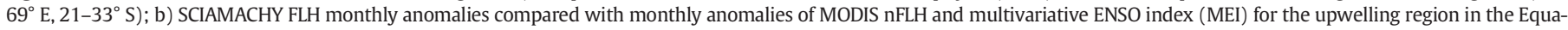
torial Pacific $\left(85-155^{\circ} \mathrm{W}, 2^{\circ} \mathrm{S}-6^{\circ} \mathrm{N}\right)(\mathrm{b})$. Correlations shown in (a) are significant at $\mathrm{p}<0.01$.

SCIAMACHY, making the separation of spectral features of fluorescence from water vapor absorption more difficult. While the retrievals' threshold for chi-square values is the same for both instruments, the chi-square values are substantially higher for GOME-2 than for SCIAMACHY (Fig. 10 b). For SCIAMACHY, $82 \%$ of pixels of the yearly composite for 2009 have a chi-square value smaller than $3 \cdot 10^{-6}$, while for GOME-2 it is only $23 \%$. We also see that the number of high chi-square vales increases for darker scenes (right panel of Fig. $10 \mathrm{~b}$ ). There are also larger errors for GOME-2 observed in the South Atlantic Anomaly region, as compared to SCIAMACHY retrieval results. It is difficult to remove those erroneous measurements from global composites by setting a lower chi-square threshold, because such observations are scattered globally. In addition, note that the GOME-2 ground scene used in this study is larger ( $40 \mathrm{~km} \times 80 \mathrm{~km})$ than SCIAMACHY, which further increases the chance of cloud contamination and thus reduces the number of ground scenes available. Overall, the GOME-2 results are significantly noisier than the SCIAMACHY results.

The regions of strong fluorescence are readily identified in GOME-2 FLH, e.g., summer phytoplankton blooms in the North Atlantic Ocean, the Benguela Upwelling or the Peruvian Coastal Upwelling. The increased chlorophyll concentration at the edges of the Antarctic coast is

Table 1

Correlation coefficients for variables shown as anomalies (an.) in Fig. 12 b, for the upwelling region in the Equatorial Pacific ( $85-155 \mathrm{~W}, 2 \mathrm{~S}-6 \mathrm{~N})$. All correlations are significant at $\mathrm{p}$ $<0.01$.

\begin{tabular}{llllll}
\hline & $\begin{array}{l}\text { SCIA FLH } \\
\text { an. }\end{array}$ & $\begin{array}{l}\text { MODIS nFLH } \\
\text { an. }\end{array}$ & $\begin{array}{l}\text { MODIS chl-a } \\
\text { an. }\end{array}$ & $\begin{array}{l}\text { MEI } \\
\begin{array}{l}\text { MODIS SST } \\
\text { an. }\end{array}\end{array}$ \\
\hline SCIA FLH an. & & 0.4418 & 0.3664 & -0.5624 & -0.5561 \\
MODIS nFLH an. & 0.4418 & & 0.7815 & -0.4188 & -0.4991 \\
MODIS chl-a an. & 0.3664 & 0.7815 & & -0.3211 & -0.5360 \\
MEI & -0.5624 & -0.4188 & -0.3211 & & 0.8362 \\
MODIS SST an. & -0.5561 & -0.4991 & -0.5360 & 0.8362 & \\
\hline
\end{tabular}

also observed. However, we have obtained a lot of negative values for chlorophyll fluorescence in most oceanic regions, and some regions of increased chlorophyll concentration, though noticeable, still display negative values (e.g., the increased chlorophyll concentration at $40^{\circ} \mathrm{S}$ belt in the Indian Ocean, or the upwelling in Equatorial Pacific).

It is advantageous to apply the fluorescence retrieval to GOME-2 data, because the satellites, which are already in orbit (MetOp-A, MetOp-B), and the upcoming satellite MetOp-C, provide potentially a long time series of chlorophyll fluorescence data. Because of the broader slit function of the GOME-2 instrument, for future studies to retrieve chl-a fluorescence at its red peak, it might be more advantageous to additionally make the use of filling-in of telluric absorption lines, following the example of Joiner et al. (2013). The application of our method to
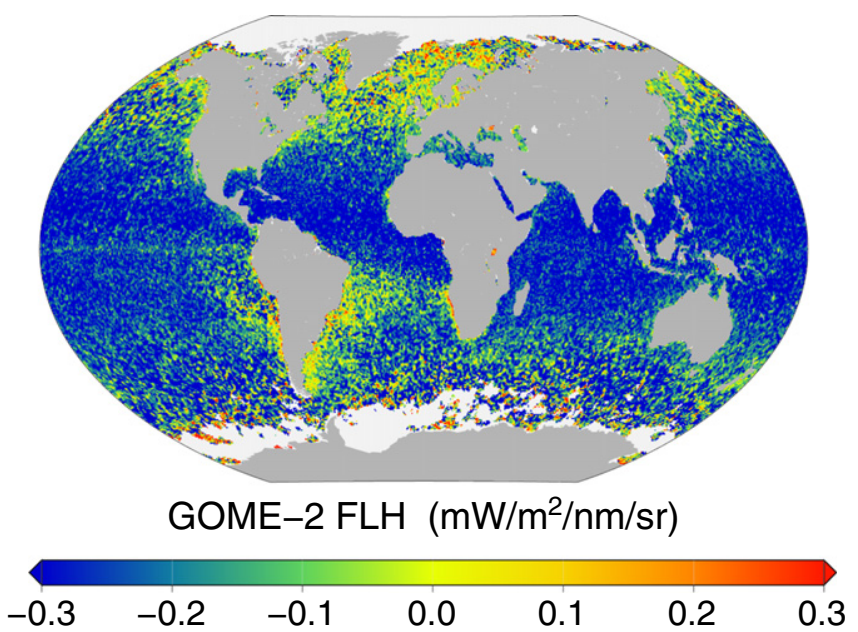

Fig. 13. Global map of FLH from GOME-2 for year 2009. 
other hyperspectral instruments will also be possible after optimization for the particular instrument.

3.5. Observations of SCIAMACHY and GOME-2 fluorescence from the terrestrial biosphere

To demonstrate the applicability of our retrieval to terrestrial chlorophyll fluorescence observations, we present initial results for land chl-a fluorescence at its red peak. In general, the fluorescence over land is more intense than that over the ocean because of the larger amount of chl-a in terrestrial plants and lower variability in the distribution of chl-a (no movement of terrestrial plants). In addition, results are not affected by the effects of VRS by water molecules.

Fig. 14 shows monthly mean values for July and December 2009 of terrestrial fluorescence emission retrieved by the DOAS algorithm for SCIAMACHY and GOME-2, compared with MODIS Terra Enhanced Vegetation Index (EVI) product, which is a popular greenness-based index. MODIS Terra EVI data used in this study were produced with the Giovanni online data system, developed and maintained by the NASA GES DISC.

Recently, two algorithms to retrieve terrestrial chl-a fluorescence at its second peak have been applied to GOME-2 (Joiner et al., 2013) and GOSAT (Guanter et al., 2012) and show good spatial agreement (Joiner et al., 2013). While our DOAS technique retrieves the red fluorescence features near $685 \mathrm{~nm}$, the other two algorithms retrieve fluorescence in the far-red emission peak near $740 \mathrm{~nm}$ (736.8 nm for GOME2, Joiner et al. (2013) and $757 \mathrm{~nm}$ for GOSAT, Guanter et al. (2012)). The wavelength used by Guanter et al. (2012) is 17 nm shifted from the far-red fluorescence peak. To compare GOME-2 results with GOSAT, Joiner et al. (2013) multiplied the $736.8 \mathrm{~nm}$ fluorescence by a factor of 0.59 , which is consistent with the spectral shape of the fluorescence emission they assumed. Assuming the same fluorescence shape for our study, values similar to those of Guanter et al. (2012) are expected to be retrieved using our DOAS technique at $685 \mathrm{~nm}$. However, the ratio between the two peaks of fluorescence cannot be assumed constant, and varied also for the top-of-canopy spectra simulated by Joiner et al. (2013).

All satellite terrestrial fluorescence retrievals (see Fig. 15a and b in Joiner et al., 2013) show similar spatial patterns of high signals in

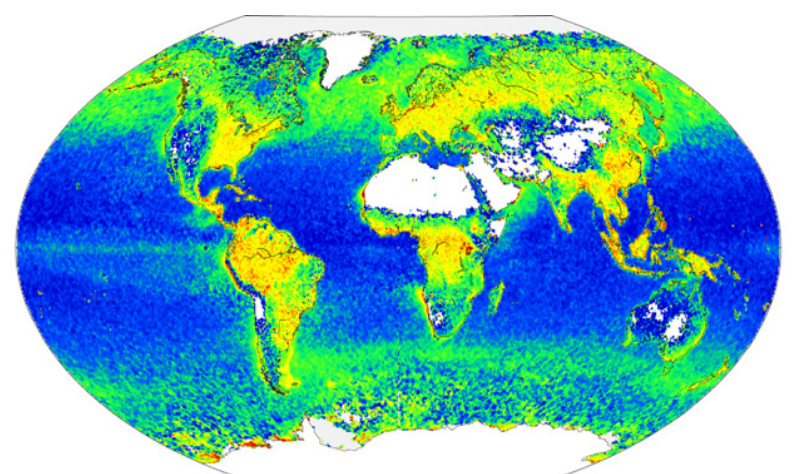

SCIAMACHY fluorescence $\left(\mathrm{mW} / \mathrm{m}^{2} / \mathrm{nm} / \mathrm{sr}\right)$

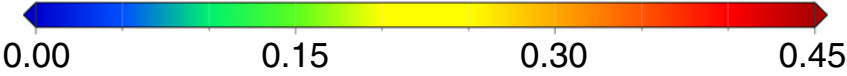

Fig. 15. Global composite of SCIAMACHY chlorophyll fluorescence for both land and ocean for years 2003-2011. The cloud threshold used for filtering the differs for ocean and land ( 0.08 and 0.16 , respectively).

areas of active vegetation and low signals in areas of barren land, as indicated by the MODIS EVI (Fig. 14). We can also observe similar differences between the seasons for all fluorescence retrievals. The highest values for July are in the east of North America. In December, we observe much weaker fluorescence from this region, and enhanced fluorescence in Central and Southern Africa during the local rainy season for all retrievals. However, regional discrepancies between different retrievals are visible, e.g., our results show higher values in the high latitudes for July. Large errors in the South Atlantic Anomaly region are also observed in our results, in particular for the GOME-2 retrieval (Fig. 10). In this region, our DOAS GOME-2 fluorescence emission values are substantially noisier than the GOME-2 retrieval results by Joiner et al. (2013), where the quality checks applied were more successful in removing erroneous measurements. Nevertheless, they also obtained the highest errors in the South Atlantic Anomaly area (Joiner et al., 2013).

Overall, our SCIAMACHY and GOME-2 fluorescence values are lower than values previously retrieved within the far-red wavelength region
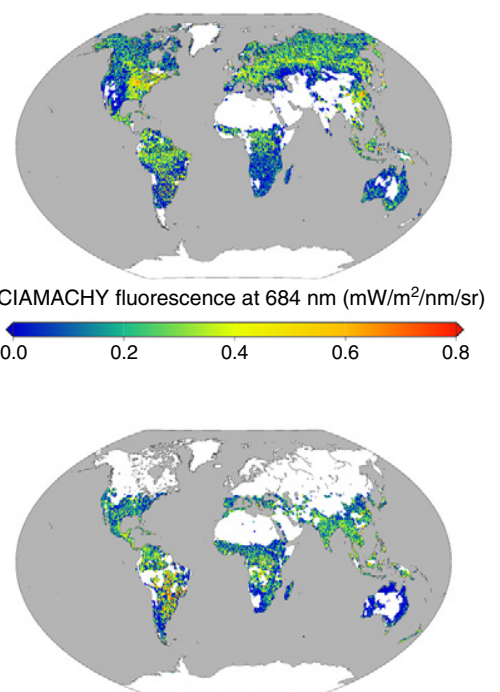

SCIAMACHY fluorescence at $684 \mathrm{~nm}\left(\mathrm{~mW} / \mathrm{m}^{2} / \mathrm{nm} / \mathrm{sr}\right)$

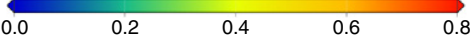

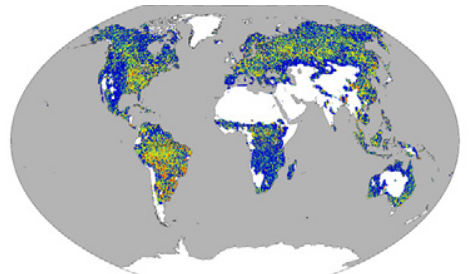

GOME-2 fluorescence $\left(\mathrm{mW} / \mathrm{m}^{2} / \mathrm{nm} / \mathrm{sr}\right)$

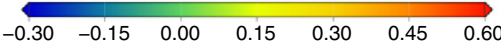

(a)

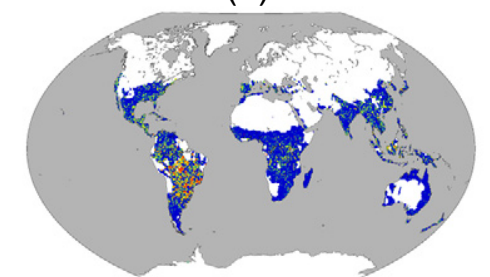

GOME-2 fluorescence $\left(\mathrm{mW} / \mathrm{m}^{2} / \mathrm{nm} / \mathrm{sr}\right)$

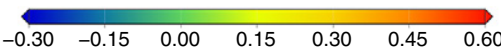

(b)

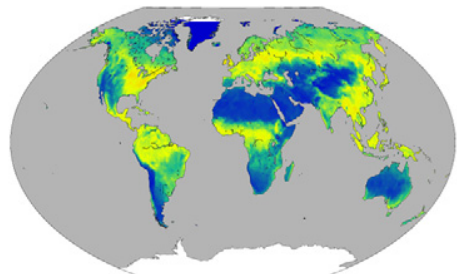

MODIS-Terra Enhanced Vegetation Index (unitless)
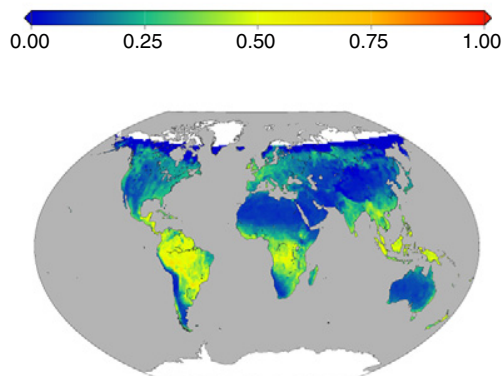

MODIS-Terra Enhanced Vegetation Index (unitless)

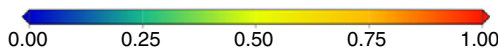

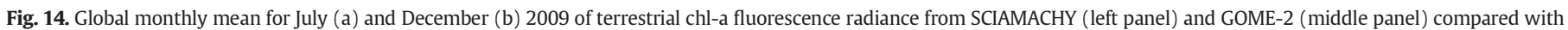
MODIS EVI (MODIS Terra Enhanced Vegetation Index, right panel). 
(Guanter et al., 2012; Joiner et al., 2013). This is particularly the case for the GOME-2 results. These data show many negative values, particularly for December (note that color scales are different for GOME-2 and SCIAMACHY). Observed discrepancies are significant, and larger than expected for the different wavelengths of the spectral windows within which the fluorescence emission is retrieved. Some of the differences between the previous far-red land fluorescence algorithms were partly assigned to the coarser GOME-2 pixels and the low sampling of GOSAT (Joiner et al., 2013). Time of overpass ( 13:00 for GOSAT) is also expected to lead to differences in fluorescence (Joiner et al., 2013).

Nevertheless, the qualitative spatial agreement of land fluorescence among the different fluorescence algorithms and EVI product, implies that it is plausible to retrieve a signal from the red fluorescence peak as well. Observed differences also reflect real differences in the fluorescence emission spectrum. Recent land fluorescence studies using GOME-2 (Joiner et al., 2013) and SCIAMACHY (Khosravi, 2012) have focused on the far red wavelength fluorescence features. However, as shown in this study, land fluorescence is also readily observed in the spectral region of the red peak of the fluorescence. In contrast to longer wavelengths, at these shorter wavelengths the fluorescence originates mostly from Photosystem II (e.g., Franck, Juneau, \& Popovic, 2002). Combining the fluorescence measurements from Photosystems I and II provides potentially new information about the terrestrial biosphere. Chlorophyll fluorescence reflects the energy portioning and its regulation within PS II, although the relationship between the fluorescence and photochemical efficiency is not constant. The signal is mostly influenced by photochemical quenching (absorbed energy used for photochemistry) and non-photochemical quenching (dissipation of energy as heat, which can be increased in the photoprotective response in the excess of light). PS I does not exhibit variable fluorescence and usually emits a low, constant background fluorescence signal due to more efficient quenching of excited states in PS I than in PS II (Blankenship, 2002).

As a result of the chlorophyll fluorescence spectrum overlapping the chlorophyll absorption spectrum, the fluoresced photons can be further reabsorbed by chlorophyll. The red fluorescence peak is much more sensitive than the near infrared peak to fluorescence re-absorption by chlorophyll, which affects the ratio of red and far red fluorescence. The decrease of this ratio is already visible on the leaf scale (the chlorophyll fluorescence is partially reabsorbed by the pigments within the leaf, Gitelson, Buschmann, \& Lichtenthaler, 1999), but is further enhanced when observed at the canopy level. This decline, which depends mainly on the canopy structure, was observed in measurements (Daumard et al., 2012; Fournier et al., 2012; Moya, Daumard, Moise, Ounis, \& Goulas, 2006), as well as in simulations (Fournier et al., 2012). The increase of chlorophyll concentration (and hence the effect of the fluorescence re-absorption) also shifts the position of the observed red peak of fluorescence toward longer wavelengths (e.g., Buschmann, 2007). Environmental stress is additionally influencing the ratio of red to far-red fluorescence (e.g., Agati et al., 2000; Genty, Wonders, \& Baker, 1990; Lichtenthaler \& Rinderle, 1988). However, the re-absorption effect driven by the canopy structure was suggested by Fournier et al. (2012) to predominate.

Satellite-derived fluorescence has been shown to have a significant relationship to modeled gross primary production (GPP) (Frankenberg et al., 2011; Guanter et al., 2012; Joiner et al., 2013). Hyperspectral measurements of fluorescence above the canopy, and especially red fluorescence, were also shown to improve the daily empirical model of GPP when used together with Photochemical Reflectance Index (Cheng et al., 2013). More on the link between chlorophyll fluorescence and photosynthesis, with focus on remote sensing application, can be found in the recent review by Porcar-Castell et al. (2014).

\section{Summary and conclusions}

In this work, we present a novel and alternative method for retrieving marine fluorescence using high spectrally resolved satellite data and a DOAS algorithm. The algorithm was developed for and tested on two hyperspectral instruments: SCIAMACHY and GOME-2. The retrieval was also applied to land areas in order to test its application for terrestrial vegetation fluorescence. The method uses filling-in of the Zeeman triplet Fraunhofer line Fe I at $684.3 \mathrm{~nm}$, which is located close to the red emission peak of fluorescence. The DOAS fitting is performed in a narrow spectral window of about $4 \mathrm{~nm}$. In order to account for broadband phenomena a polynomial of low order was subtracted. Because of the influence of water vapor absorption and Raman scattering on the retrieval, we implemented a correction scheme which utilizes fits carried out in two other spectral regions for those specific targets. Additionally, we added a conversion dependent on the elastically scattered radiance. Those corrections are based on simulations with the coupled ocean-atmosphere radiative transfer model SCIATRAN (Blum et al., 2012; Rozanov et al., 2014) that were optimized for the optical characteristics of each instrument.

Marine fluorescence results from SCIAMACHY and GOME-2 show overall good spatial agreement. Their global distribution agrees reasonably well with MODIS nFLH in regions where high MODIS chlorophyll concentration are observed. Our study has demonstrated for the first time that the weak fluorescence signal is retrievable from the oceans using hyperspectral data. Noting that our results deliver the fluorescence or FLH from the filling-in of the Fe I Fraunhofer line and that the MODIS nFLH uses three bands and the baseline algorithm, our fluorescence observations verify the MODIS nFLH product. The latter and the MERIS data product (Gower \& King, 2007) were up to this publication the only available data sets to assess chlorophyll fluorescence from the ocean on the global scale. The observed quantitative differences between SCIAMACHY and GOME-2 DOAS FLH and MODIS nFLH arise from differences among the instruments, retrieval methods, spatial and temporal sampling, overpass time and the spectral shape of the fluorescence emission as well as difference between FLH and nFLH representation of fluorescence data. Hence, our fluorescence results can be used in the future for further studies and interpretation of chl-a fluorescence to better understand the fluorescence signal seen in both types of algorithms and its dependency on the algorithms and instruments for different marine regions.

Clearly, MODIS nFLH results are less noisy, but with an increase in spatial resolution and sampling of future hyperspectral instruments, the quality of DOAS FLH results will improve. In addition, hyperspectral measurements are not as susceptible to certain problems as the multispectral nFLH data products, which arise from backscattered light by particulate matter, such as detritus, or phycocyanin fluorescence. For our DOAS retrieval, we obtain better results for SCIAMACHY where the spectral resolution is higher and the size of the footprint is smaller. However, GOME-2 results are still valuable and deliver a future perspective for this algorithm. There are now two GOME-2 instruments orbiting Earth and as the pixel size of first of them (MetOp-A) was reduced, we hope to obtain more cloud-free pixels and better results from July 2013 onwards. We have shown that hyperspectral instruments can be in principle a new source of marine fluorescence information, independent of multispectral instruments. In the future, modified versions of our approach can also be applied to the measurements of the TROPOMI Instrument onboard Sentinel 5 Precursor, planned for launch in 2016 (Veefkind et al., 2012) and the Copernicus Sentinel 5 instruments which will fly on the MetOp second generation platforms from 2020 onwards. Adapted and adjusted algorithms, when applied to more instruments, could provide global and more frequent fluorescence information, utilizing the different times of satellites overpasses, thus providing information about the diurnal cycle of chlorophyll fluorescence.

The ability to observe fluorescence from land vegetation in the Fe I Fraunhofer line in the spectral window $681.8 \mathrm{~nm}$ to $685.5 \mathrm{~nm}$ is also reported. This is the first example of retrieving chlorophyll fluorescence from space for the SCIAMACHY instrument for land vegetation. As terrestrial fluorescence has been extensively retrieved and studied in its far-red peak (e.g., Guanter et al., 2012; Joiner et al., 2013), it is important 
to prove that the signal from the red peak of fluorescence can be observed. This retrieval approach and the new data set should attract the attention of the terrestrial fluorescence community to the red peak of chlorophyll fluorescence. Knowledge about the strength of two fluorescence peaks can be used for several applications, e.g., the determination of the chlorophyll content at leaf level (Gitelson \& Merzlyak, 1997; Gitelson et al., 1999) or of the canopy structure (Fournier et al., 2012). Furthermore, changes in fluorescence ratio also occur in response to environmental factors, like temperature (Agati et al., 2000) and light (Genty et al., 1990). More detailed information about fluorescence will be valuable for complex vegetation studies. What is additionally interesting, is that we can retrieve chlorophyll fluorescence from both the land and the ocean with the same approach, which has never been done before (see Fig. 15). In conclusion knowledge obtained from the observation of the red peak of fluorescence will contribute to combined studies of fluorescence, both in the marine and land environment on the global scale.

\section{Acknowledgements}

Aleksandra Wolanin gratefully acknowledges financial support provided by the Earth System Science Research School (ESSReS) VH-KO200, an initiative of the Helmholtz Association of German Research Centres (HGF) at the Alfred Wegener Institute for Polar and Marine Research (AWI), and by the HGF Innovative Network Fund (PHYTOOPTICS project) VH-NG-300. Funding of the contribution of MV came from a DLR/BmWi grant (FLUS, FKZ:50EE1260) which is highly acknowledged. Authors thank DLR and ESA for SCIAMACHY level-1 data. We also acknowledge the MODIS mission scientists and associated NASA personnel for the production of the data used in this research effort. Analyses and visualizations were produced with the Giovanni online data system, developed and maintained by the NASA GES DISC.

\section{References}

Abbott, M. R., \& Letelier, R. M. (1999). Algorithm theoretical basis document chlorophyll fluorescence (MODIS product number 20). NASA (http://www.modis.gsfc.nasa.gov/ data/atbd).

Agati, G., Cerovic, Z. G., \& Moya, I. (2000). The effect of decreasing temperature up to chilling values on the in vivo F685/F735 chlorophyll fluorescence ratio in Phaseolus vulgaris and Pisum sativum: The role of the Photosystem I contribution to the $735 \mathrm{~nm}$ fluorescence band. Photochemistry and Photobiology, 72(1), 75-84.

Babin, M., Morel, A., \& Gentili, B. (1996). Remote sensing of sea surface sun-induced chlorophyll fluorescence: Consequences of natural variations in the optical characteristics of phytoplankton and the quantum yield of chlorophyll a fluorescence. Internationa Journal of Remote Sensing, 17(12), 2417-2448.

Barber, R. T., \& Chavez, F. P. (1983). Biological consequences of El Niño. Science, 222(4629), 1203-1210.

Barber, R. T., \& Chávez, F. P. (1986, January). Ocean variability in relation to living resources during the 1982-83 El Niño. Nature, 319(6051), 279-285.

Behrenfeld, M. J., Westberry, T. K., Boss, E., O'Malley, R. T., Siegel, D. A., Wiggert, J. D., et al. (2009). Satellite-detected fluorescence reveals global physiology of ocean phytoplankton. Biogeosciences, 6, 779-794.

Blankenship, R. E. (Ed.). (2002). Molecular mechanisms of photosynthesis. Oxford, UK: Blackwell Science Ltd.

Blum, M., Rozanov, V. V., Burrows, J. P., \& Bracher, A. (2012). Coupled ocean-atmosphere radiative transfer model in the framework of software package SCIATRAN: Selected comparisons to model and satellite data. Advances in Space Research, 49(12), $1728-1742$.

Bodhaine, B. A., Wood, N. B., Dutton, E. G., \& Slusser, J. R. (1999). On Rayleigh optical depth calculations. Journal of Atmospheric and Oceanic Technology, 16(11), 1854-1861.

Bovensmann, H., Burrows, J. P., Buchwitz, M., Frerick, J., Noël, S., Rozanov, V. V., et al. (1999). SCIAMACHY: Mission objectives and measurement modes. Journal of the Atmospheric Sciences, 56(2), 127-150.

Boyce, D. G., Lewis, M. R., \& Worm, B. (2010). Global phytoplankton decline over the past century. Nature, 466(7306), 591-596.

Bracher, A., Vountas, M., Dinter, T., Burrows, J. P., Röttgers, R., \& Peeken, I. (2009). Quantitative observation of cyanobacteria and diatoms from space using PhytoDOAS on SCIAMACHY data. Biogeosciences, 6, 751-764

Burrows, J. P., Hölzle, E., Goede, A. P. H., Visser, H., \& Fricke, W. (1995). SCIAMACHY-Scanning imaging absorption spectrometer for atmospheric chartography. Acta Astronautica, 35(7), 445-451.

Burrows, J. P., Weber, M., Buchwitz, M., Rozanov, V. V., Ladstätter-Weißenmayer, A. Richter, A., et al. (1999). The global ozone monitoring experiment (GOME):
Mission concept and first scientific results. Journal of the Atmospheric Sciences, $56(2), 151-175$

Buschmann, C. (2007). Variability and application of the chlorophyll fluorescence emission ratio red/far-red of leaves. Photosynthesis Research, 92(2), 261-271.

Callies, J., Corpaccioli, E., Eisinger, M., Hahne, A., \& Lefebvre, A. (2000). GOME-2MetOP's second-generation sensor for operational ozone monitoring. ESA Bulletin, 102, 28-36.

Chavez, F. P., Strutton, P. G., Friederich, G. E., Feely, R. A., Feldman, G. C., Foley, D. G., et al. (1999). Biological and chemical response of the equatorial Pacific Ocean to the 1997-98 El Niño. Science, 286(5447), 2126-2131.

Cheng, Y. -B., Middleton, E., Zhang, Q., Huemmrich, K., Campbell, P., Corp, L., et al. (2013). Integrating solar induced fluorescence and the photochemical reflectance index for estimating gross primary production in a cornfield. Remote Sensing, 5(12), $6857-6879$.

Daumard, F., Goulas, Y., Champagne, S., Fournier, A., Ounis, A., Olioso, A., et al. (2012, November). Continuous monitoring of canopy level sun-induced chlorophyll fluorescence during the growth of a sorghum field. IEEE Transactions on Geoscience and Remote Sensing, 50(11), 4292-4300.

Doney, S. C., Ruckelshaus, M., Emmett Duffy, J., Barry, J. P., Chan, F., English, C. A., et al. (2012). Climate change impacts on marine ecosystems. Annual Review of Marine Science, 4(1), 11-37.

Eisinger, M., Richter, A., Ladstätter-Weißnmayer, A., \& Burrows, J. P. (1997). DOAS zenith sky observations: 1 . BrO measurements over Bremen $\left(53^{\circ} \mathrm{N}\right) 199-1994$. Journal of Atmospheric Chemistry, 26(1), 93-108.

Falkowski, P. G. (1998). Biogeochemical controls and feedbacks on ocean primary production. Science, 281(5374), 200-206.

Falkowski, P. G., \& Kolber, Z. (1995). Variations in chlorophyll fluorescence yields in phytoplankton in the world oceans. Functional Plant Biology, 22(2), 341-355.

Field, C. B. (1998). Primary production of the biosphere: Integrating terrestrial and oceanic components. Science, 281(5374), 237-240.

Fournier, A., Daumard, F., Champagne, S., Ounis, A., Goulas, Y., \& Moya, I. (2012). Effect of canopy structure on sun-induced chlorophyll fluorescence. ISPRS Journal of Photogrammetry and Remote Sensing, 68, 112-120.

Franck, F., Juneau, P., \& Popovic, R. (2002). Resolution of the Photosystem I and Photosystem II contributions to chlorophyll fluorescence of intact leaves at room temperature. Biochimica et Biophysica Acta (BBA) - Bioenergetics, 1556(2-3), 239-246.

Frankenberg, C., Fisher, J. B., Worden, J., Badgley, G., Saatchi, S. S., Lee, J. -E., et al. (2011). New global observations of the terrestrial carbon cycle from GOSAT: Patterns of plant fluorescence with gross primary productivity. Geophysical Research Letters, 38(17), L17706.

Genty, B., Wonders, J., \& Baker, N. R. (1990). Non-photochemical quenching of $F_{o}$ in leaves is emission wavelength dependent: consequences for quenching analysis and its interpretation. Photosynthesis Research, 26(2), 133-139.

Gitelson, A. A. (1992). The peak near $700 \mathrm{~nm}$ on radiance spectra of algae and water: Relationships of its magnitude and position with chlorophyll concentration. International Journal of Remote Sensing, 13(17), 3367-3373.

Gitelson, A. A., Buschmann, C., \& Lichtenthaler, H. K. (1999). The chlorophyll fluorescence ratio $\mathrm{F}_{735} / \mathrm{F}_{700}$ as an accurate measure of the chlorophyll content in plants. Remote Sensing of Environment, 69(3), 296-302.

Gitelson, A. A., \& Merzlyak, M. N. (1997). Remote estimation of chlorophyll content in higher plant leaves. International Journal of Remote Sensing, 18(12), 2691-2697.

Gordon, H. R., \& Clark, D. K. (1981). Clear water radiances for atmospheric correction of coastal zone color scanner imagery. Applied Optics, 20(24), 4175-4180.

Gordon, H. R., \& Voss, K. J. (2004). MODIS normalized water-leaving radiance algorithm theoretical basis document (MOD 18). NASA (http://www.modis.gsfc.nasa.gov/data/ atbd).

Gower, J. F. R., Brown, L., \& Borstad, G. A. (2004). Observation of chlorophyll fluorescence in west coast waters of Canada using the MODIS satellite sensor. Canadian Journal of Remote Sensing, 30(1), 17-25.

Gower, J. F. R., \& King, S. (2004). Satellite fluorescence as a measure of ocean surface chlorophyll. Gayana (Concepción), 68(2).

Gower, J. F. R., \& King, S. (2007). Validation of chlorophyll fluorescence derived from MERIS on the west coast of Canada. International Journal of Remote Sensing, 28(3-4), 625-635.

Gower, J. F. R., \& King, S. (2012). Use of satellite images of chlorophyll fluorescence to monitor the spring bloom in coastal waters. International Journal of Remote Sensing, 33(23), 7469-7481.

Grainger, J. F., \& Ring, J. (1962). Anomalous Fraunhofer line profiles. Nature, 193(4817) $762-762$.

Gregg, W. W. (2003). Ocean primary production and climate: Global decadal changes. Geophysical Research Letters, 30(15), 1809.

Gregg, W. W., Casey, N. W., \& McClain, C. R. (2005). Recent trends in global ocean chlorophyll. Geophysical Research Letters, 32(3), L03606.

Guanter, L., Frankenberg, C., Dudhia, A., Lewis, P. E., Gómez-Dans, J., Kuze, A., et al. (2012). Retrieval and global assessment of terrestrial chlorophyll fluorescence from GOSAT space measurements. Remote Sensing of Environment, 121, 236-251.

Halthore, R. N., \& Caffrey, P. F. (2006). Measurement and modeling of background aerosols in remote marine atmospheres: Implications for sea salt flux. Geophysical Research Letters, 33(14), L14819.

Haltrin, V. I., \& Kattawar, G. W. (1993). Self-consistent solutions to the equation of transfer with elastic and inelastic scattering in oceanic optic. Applied Optics, 32(27), 5356-5367.

Hofmann, M., Worm, B., Rahmstorf, S., \& Schellnhuber, H. J. (2011). Declining ocean chlorophyll under unabated anthropogenic $\mathrm{CO}_{2}$ emissions. Environmental Research Letters, 6(3), 034035 
Huhn, F., von Kameke, A., Pérez-Muñuzuri, V., Olascoaga, M. J., \& Beron-Vera, F. J. (2012, March). The impact of advective transport by the South Indian Ocean. Countercurrent on the Madagascar plankton bloom. Geophysical Research Letters, 39(6) (n/a-n/a).

Huot, Y., \& Babin, M. (2010). Overview of fluorescence protocols: Theory, basic concepts, and practice. In D. J. Suggett, O. Prášil, \& M. A. Borowitzka (Eds.), Chlorophyll a fluorescence in aquatic sciences: Methods and applications (pp. 31-74). Netherlands: Springer.

Huot, Y., Franz, B. A., \& Fradette, M. (2013). Estimating variability in the quantum yield of sun-induced chlorophyll fluorescence: A global analysis of oceanic waters. Remote Sensing of Environment, 132, 238-253.

IPCC (2013). Climate change 2013: The physical science basis. Working Group I contribution to the IPCC 5th assessment report - Changes to the underlying scientific/technical assessment. Cambridge University Press.

Joiner, J., Guanter, L., Lindstrot, R., Voigt, M., Vasilkov, A. P., Middleton, E. M., et al. (2013). Global monitoring of terrestrial chlorophyll fluorescence from moderate-spectralresolution near-infrared satellite measurements: Methodology, simulations, and application to GOME-2. Atmospheric Measurement Techniques, 6(10), 2803-2823.

Joiner, J., Yoshida, Y., Vasilkov, A. P., Yoshida, Y., Corp, L. A., \& Middleton, E. M. (2011). First observations of global and seasonal terrestrial chlorophyll fluorescence from space. Biogeosciences, 8(3), 637-651.

Kattawar, G. W., \& Xu, X. (Oct 1992). Filling in of Fraunhofer lines in the ocean by Raman scattering. Applied Optics, 31(30), 6491-6500.

Khosravi, N. (2012). Terrestrial plant fluorescence as seen from satellite data. (M.sc.-thesis) University of Bremen.

Krause, G. H., \& Weis, E1. (1991). Chlorophyll fluorescence and photosynthesis: The basics. Annual Review of Plant Biology, 42(1), 313-349.

Lévy, M., Shankar, D., André, J. -M., Shenoi, S. S. C., Durand, F., \& de Boyer Montégut, C. (2007, December). Basin-wide seasonal evolution of the Indian Ocean's phytoplankton blooms. Journal of Geophysical Research, 112(C12).

Lichtenthaler, H. K., \& Rinderle, U. (1988). The role of chlorophyll fluorescence in the detection of stress conditions in plants. CRC, Critical Reviews in Analytical Chemistry, 19(sup1), S29-S85.

Longhurst, A. (2001). A major seasonal phytoplankton bloom in the Madagascar Basin. Deep Sea Research Part I: Oceanographic Research Papers, 48(11), 2413-2422.

Macintyre, H. L., Lawrenz, E., \& Richardson, T. L. (2010). Taxonomic discrimination of phytoplankton by spectral fluorescence. In D. J. Suggett, O. Prášil, \& M. A. Borowitzka (Eds.), Chlorophyll a fluorescence in aquatic sciences: Methods and applications (pp. 31-74). Netherlands: Springer.

Mackas, D. L. (2011). Does blending of chlorophyll data bias temporal trend? Nature, 472(7342), E4-E5.

Maxwell, K. (2000). Chlorophyll fluorescence-A practical guide. Journal of Experimental Botany, 51(345), 659-668.

McKibben, S. M., Strutton, P. G., Foley, D. G., Peterson, T. D., \& White, A. E. (2012). Satellitebased detection and monitoring of phytoplankton blooms along the Oregon coast. Journal of Geophysical Research, 117(C12002).

McQuatters-Gollop, A., Raitsos, D. E., Edwards, M., Pradhan, Y., Mee, L. D., Lavender, S. J. et al. (2007). A long-term chlorophyll data set reveals regime shift in North Sea phytoplankton biomass unconnected to nutrient trends. Limnology and Oceanography, 52(2), 635-648.

McQuatters-Gollop, A., Reid, P. C., Edwards, M., Burkill, P. H., Castellani, C., Batten, S., et al. (2011). Is there a decline in marine phytoplankton? Nature, 472(7342), E6-E7.

Millie, D. F., Schofield, O. M., Kirkpatrick, G. J., Johnsen, G., \& Evens, T. J. (2002). Using absorbance and fluorescence spectra to discriminate microalgae. European Journal of Phycology, 37(3), 313-322.

Mobley, C. D. (1994). Light and water: Radiative transfer in natural waters. San Diego, Calif. [u.a.]: Academic Press.

Morrison, J. R., \& Goodwin, D. S. (2010). Phytoplankton photocompensation from spacebased fluorescence measurements. Geophysical Research Letters, 37(6), L06603.

Moya, I., Daumard, F., Moise, N., Ounis, A., \& Goulas, Y. (2006). First airborne multiwavelength passive chlorophyll fluorescence measurements over La Mancha (Spain) fields. 2nd International Symposium on Recent Advances in Quantitative Remote Sensing: RAQRS'II, 25-29th September, Torrent (Valencia)-Spain (pp. 820-825).

Munro, R., Eisinger, M., Anderson, C., Callies, J., Corpaccioli, E., Lang, R., et al. (2006). GOME-2 on MetOp. Proc. of the 2006 EUMETSAT Meteorological Satellite Conference, Helsinki, Finland, EUMETSAT (pp. 48).

Neville, R. A., \& Gower, J. F. R. (1977). Passive remote sensing of phytoplankton via chlorophyll $\alpha$ fluorescence. Journal of Geophysical Research, 82(24), 3487-3493.

Noël, S., Buchwitz, M., \& Burrows, J. P. (2004). First retrieval of global water vapour column amounts from SCIAMACHY measurements. Atmospheric Chemistry and Physics, 4, 111-125.

Noël, S., Buchwitz, M., Bovensmann, H., \& Burrows, J. P. (2005). Validation of SCIAMACHY AMC-DOAS water vapour columns. Atmospheric Chemistry and Physics, 5, 1835-1841.

Noël, S., Mieruch, S., Bovensmann, H., \& Burrows, J. P. (2008). Preliminary results of GOME-2 water vapour retrievals and first applications in polar regions. Atmospheric Chemistry and Physics, 8(6), 1519-1529.

O'Malley, R. T., Behrenfeld, M. J., Westberry, T. K., Milligan, A. J., Shang, S., \& Yan, J. (July 2014). Geostationary satellite observations of dynamic phytoplankton photophysiology: GOCI fluorescence. Geophysical Research Letters, 41(14), 5052-5059.

Olonscheck, D., Hofmann, M., Worm, B., \& Schellnhuber, H. J. (2013). Decomposing the effects of ocean warming on chlorophyll $a$ concentrations into physically and biologically driven contributions. Environmental Research Letters, 8(1), 014043.

Perner, D., \& Platt, U. (1979). Detection of nitrous acid in the atmosphere by differential optical absorption. Geophysical Research Letters, 6(12), 917-920.

Peters, E., Wittrock, F., Richter, A., Alvarado, L. M. A., Rozanov, V. V., \& Burrows, J. P. (2014). Liquid water absorption and scattering effects in DOAS retrievals over oceans. Atmospheric Measurement Techniques, 7(12), 4203-4221.
Porcar-Castell, A., Tyystjarvi, E., Atherton, J., van der Tol, C., Flexas, J., Pfundel, E. E., et al. (2014). Linking chlorophyll a fluorescence to photosynthesis for remote sensing applications: Mechanisms and challenges. Journal of Experimental Botany, 65(15) 4065-4095.

Raj, R. P., Peter, B. N., \& Pushpadas, D. (September 2010). Oceanic and atmospheric influences on the variability of phytoplankton bloom in the southwestern Indian Ocean. Journal of Marine Systems, 82(4), 217-229.

Richter, A., Burrows, J. P., Nüß, H., Granier, C., \& Niemeier, U. (2005). Increase in tropospheric nitrogen dioxide over China observed from space. Nature, 437(7055), 129-132.

Rousseaux, C. S., \& Gregg, W. W. (2012, October). Climate variability and phytoplankton composition in the Pacific Ocean. Journal of Geophysical Research, 117(C10).

Rozanov, V. V., \& Rozanov, A. V. (2010). Differential optical absorption spectroscopy (DOAS) and air mass factor concept for a multiply scattering vertically inhomogeneous medium: Theoretical consideration. Atmospheric Measurement Techniques, 3 , 751-780.

Rozanov, V. V., Rozanov, A. V., Kokhanovsky, A. A., \& Burrows, J. P. (2014). Radiative transfer through terrestrial atmosphere and ocean: Software package SCIATRAN. Journal of Quantitative Spectroscopy and Radiative Transfer, 133(0), 13-71.

Rozanov, V. V., \& Vountas, M. (2014). Radiative transfer equation accounting for rotational Raman scattering and its solution by the discrete-ordinates method. Journal of Ouantitative Spectroscopy and Radiative Transfer, 133, 603-618.

Ryan, J. P., Polito, P. S., Strutton, P. G., \& Chavez, F. P. (2002). Unusual large-scale phytoplankton blooms in the equatorial Pacific. Progress in Oceanography, 55(3) 263-285.

Rykaczewski, R. R., \& Dunne, J. P. (2011). A measured look at ocean chlorophyll trends. Nature, 472(7342), E5-E6.

Sadeghi, A., Dinter, T., Vountas, M., Taylor, B. B., Altenburg-Soppa, M., Peeken, I., et al (2012, November). Improvement to the PhytoDOAS method for identification of coccolithophores using hyper-spectral satellite data. Ocean Science, 8(6), 1055-1070.

Schallenberg, C., Lewis, M. R., Kelley, D. E., \& Cullen, J. J. (2008). Inferred influence of nutrient availability on the relationship between sun-induced chlorophyll fluorescence and incident irradiance in the Bering Sea. Journal of Geophysical Research, 113(C07046).

Siegel, D. A. (2010). Century of phytoplankton change. Nature, 466, 569-571.

Signorini, S. R., \& McClain, C. R. (2007, November). Large-scale forcing impact on biomass variability in the South Atlantic bight. Geophysical Research Letters, 34(21).

Signorini, S. R., \& McClain, C. R. (2012, November). Subtropical gyre variability as seen from satellites. Remote Sensing Letters, 3(6), 471-479.

Simis, S. G. H., Huot, Y., Babin, M., Seppälä, J., \& Metsamaa, L. (2012). Optimization of variable fluorescence measurements of phytoplankton communities with cyanobacteria Photosynthesis Research, 112(1), 13-30.

Sinnhuber, B. -M., Sheode, N., Sinnhuber, M., Chipperfield, M. P., \& Feng, W. (2009) The contribution of anthropogenic bromine emissions to past stratospheric ozone trends: A modelling study. Atmospheric Chemistry and Physics, 9, $2863-2871$.

Srokosz, M. A. (2004). A possible plankton wave in the Indian Ocean. Geophysical Research Letters, 31(13)

Srokosz, M. A., \& Quartly, G. D. (2013, January). The Madagascar bloom: A serendipitous study: Madagascar bloom: A serendipitous study. Journal of Geophysical Research Oceans, 118(1), 14-25.

Strutton, P. G., \& Chavez, F. P. (2000). Primary productivity in the equatorial Pacific during the 1997-1998 El Niño. Journal of Geophysical Research, 105(C11), 26089.

Strutton, P. G., Evans, W., \& Chavez, F. P. (2008, June). Equatorial pacific chemical and biological variability, 1997-2003: Pacific chemical and biological variability. Globa Biogeochemical Cycles, 22(2) (n/a-n/a).

Uz, B. M. (2007, September). What causes the sporadic phytoplankton bloom southeast of Madagascar? Journal of Geophysical Research, 112(C9).

Vasilkov, A. P. (2002). Ocean Raman scattering in satellite backscatter UV measurements Geophysical Research Letters, 29(17).

Veefkind, J. P., Aben, I., McMullan, K., Förster, H., de Vries, J., Otter, G., et al. (2012) TROPOMI on the ESA sentinel-5 precursor: A GMES mission for global observations of the atmospheric composition for climate, air quality and ozone layer applications. Remote Sensing of Environment, 120, 70-83.

Vountas, M., Dinter, T., Bracher, A., Burrows, J. P., \& Sierk, B. (2007). Spectral studies of ocean water with space-borne sensor SCIAMACHY using differential optical absorption spectroscopy (DOAS). Ocean Science, 3(3), 429-440.

Vountas, M., Richter, A., Wittrock, F., \& Burrows, J. P. (2003). Inelastic scattering in ocean water and its impact on trace gas retrievals from satellite data. Atmospheric Chemistry and Physics, 3(5), 1365-1375.

Vountas, M., Rozanov, V. V., \& Burrows, J. P. (1998). Ring effect: Impact of rotational Raman scattering on radiative transfer in Earth's atmosphere. Journal of Quantitative Spectroscopy and Radiative Transfer, 60(6), 943-961.

Wagner, T., Beirle, S., Deutschmann, T., Grzegorski, M., \& Platt, U. (2007). Satellite monitoring of different vegetation types by differential optical absorption spectroscopy (DOAS) in the red spectral range. Atmospheric Chemistry and Physics 7(1), 69-79.

Wernand, M. R., van der Woerd, H. J., \& Gieskes, W. W. C. (2013). Trends in ocean colour and chlorophyll concentration from 1889 to 2000, worldwide. PLOS ONE, 8(6), e63766.

Westberry, T. K., Behrenfeld, M. J., Milligan, A. J., \& Doney, S. C. (2013). Retrospective satellite ocean color analysis of purposeful and natural ocean iron fertilization. Deep Sea Research Part I: Oceanographic Research Papers, 73, 1-16.

Wolter, K., \& Timlin, M. S. (1998). Measuring the strength of ENSO events: How does 1997/98 rank? Weather, 53(9), 315-324. 
Wynne, T. T., Stumpf, R. P., \& Briggs, T. O. (2013). Comparing MODIS and MERIS spectral shapes for cyanobacterial bloom detection. International Journal of Remote Sensing, 34(19), 6668-6678.

Wynne, T. T., Stumpf, R. P., Tomlinson, M. C., Fahnenstiel, G. L., Dyble, J., Schwab, D. J., et al. (2013). Evolution of a cyanobacterial bloom forecast system in western Lake Erie: Development and initial evaluation. Journal of Great Lakes Research, 39, 90-99.
Wynne, T. T., Stumpf, R. P., Tomlinson, M. C., Warner, R. A., Tester, P. A., Dyble, J., et al. (2008). Relating spectral shape to cyanobacterial blooms in the Laurentian Great Lakes. International Journal of Remote Sensing, 29(12), 3665-3672.

Wyrtki, K. (September 1981). An estimate of equatorial upwelling in the Pacific. Journal of Physical Oceanography, 11(9), 1205-1214.

Xing, X. -G., Zhao, D. -Z., Liu, Y. -G., Yang, J. -H., Xiu, P., \& Wang, L. (2007). An overview of remote sensing of chlorophyll fluorescence. Ocean Science Journal, 42(1), 49-59. 